\title{
Constituent order in Serbian Sign Language declarative clauses
}

\section{Glossa}

a journal of general linguistics

\author{
RESEARCH
}

\section{DRAGANA RAIČEVIĆ BAJIĆ $\circledast$ \\ MYRIAM VERMEERBERGEN (1)}

ADAM SCHEMBRI (D)

MIEKE VAN HERREWEGHE (1)

*Author affiliations can be found in the back matter of this article

\begin{abstract}
Constituent order can encode grammatical relations in a language. The visual-spatial modality imbues sign languages with characteristics such as simultaneity or the use of space which raise the question of the appropriate unit of analysis in constituent order studies. In this paper, we provide empirical evidence on the order of core constituents in elicited declarative clauses for non-reversible, reversible and locative states-ofaffairs in Serbian Sign Language (SZJ). Forty (near-)native deaf SZJ signers, ranging in age between 18 and 70 years old, participated in the data-collection. We consider linguistic and social factors in 810 clauses elicited for the purposes of this study. Our findings suggest that SVO is a preferred order in non-locative clauses with two overtly expressed arguments, whilst GROUND-FIGURE-LOCATIVE RELATION is the most frequent pattern in locative clauses. We argue that our results provide some support for the claim that sign language discourse can be analysed in terms of constituent order in the clause, but that other strategies typical of the visual modality such as the simultaneous expression of core constituents, and manual and non-manual features, the use of space, core argument incorporation into the form of the verb and core argument omission, complicate the traditional notion of sequential constituent order clause as a central grammatical element in SZI and, by extension, in other sign languages. Consequently, the description of relations between core constituents calls for careful consideration and analysis of different types of data as a way of gaining a clearer insight into the nature of a sign language.
\end{abstract}

CORRESPONDING AUTHOR:

\section{Dragana Raičević Bajić}

Linguistics Department, Ghent University, Blandijnberg 2, 9000 Ghent, Belgium

dragana.raicevic@ugent.be

\section{KEYWORDS:}

sign language; constituent order; declarative clauses; Serbian Sign Language

TO CITE THIS ARTICLE: Raičević Bajić, Dragana, Myriam Vermeerbergen, Adam Schembri and Mieke Van Herreweghe. 2021. Constituent order in Serbian Sign Language declarative clauses. Glossa: a journal of general linguistics 6(1): 39. 1-32. DOI: https://doi.org/10.5334/ gjgl.1357 


\section{Introduction}

In this article, we focus on constituent order in Serbian Sign Language (srpski znakovni jezik or SZJ), a largely under-documented sign language (SL). The main research question of this study addresses the manner in which the predicate and the nominal phrases in single active declarative clauses are ordered. More specifically, the goals of this study are to determine the position of a predicate with respect to its arguments in declarative clauses of three types, i.e. non-reversible, reversible, and locative, and to get an indication of the role the factors that have been claimed to influence constituent order in other SLs play in SZJ. While the topic of constituent order in declarative clauses has largely featured in international SL research (e.g., Brennan \& Turner 1994; Johnston et al. 2007; Napoli \& Sutton-Spence 2014), this is the first comprehensive study on constituent order in SZJ.

\section{Formal versus cognitive/functional approach to constituent order in sign languages}

Typological studies that focus on constituent order in (sign) languages can roughly be divided into two groups. Criteria for such a division are based on a theoretical orientation which has implications for the basic unit of analysis, and the nature of relations that hold between the core constituents, that is, whether the relations are best described as grammatical, semantic, pragmatic or pragmatic-semantic.

The first group of studies examine simple declarative ditransitive clauses by describing constituent order according to the grammatical relations of subject, object, and verb (see Napoli \& Sutton-Spence 2014 for an overview). Most studies in this group take a formal linguistic approach and as such make two assumptions: first, that a clause is a fundamental grammatical unit in discourse, and second, that the subject constitutes a universal grammatical role.

The second group of studies that base their analyses on a cognitive/functional approach question the universality of grammatical relations (Dryer 1997; Croft 2001) and take a provisional view of the traditional notion of a clause. In cognitive/functional approaches, constituent order tends to be described in terms of information structure, using notions such as topic-comment (Li \& Thompson 1976), focus-background (Givón 2001), and given-new (Prince 1981), or in terms of conceptual relations (Croft 2001). Thus, a major issue on constituent order within a cognitive/functional framework which SL studies have tried to address is the nature of relations between core constituents. Anderson (1978), for example, claims that constituent order in American Sign Language (ASL) does not rely on grammatical relations, but on information structure. Research into Danish Sign Language (DTS) similarly suggests that the grammatical role of subject is absent from DTS (Engberg-Pedersen 2002), while in a recent corpus-based study on clause constituents in Auslan (the majority SL in Australia), Johnston (2019a) proposed that Auslan is a pragmatic-semantic constituent order language lacking grammatical relations. Pertaining to the issue of describing core constituents in SLs are the phenomena of core argument omission, and simultaneity, both of which raise the question of the appropriate unit of analysis in constituent order studies. Ferrara (2012), for example, reported a high number of verb-only and verbless attributive clauses in her Auslan dataset consisting of free conversations and narratives. When a core argument is omitted, the information about the participants of an action and/or about the action itself has been suggested to be a result of the referential cohesion and the context of the utterance (Johnston \& Schembri 2007; McKee et al. 2011). Cohesion in SLs includes the meaningful placement of signs in space whereby an association between a location and an absent referent is established, for instance. Another discourse feature that plays an important role in participant identification, especially in clauses without overt core arguments, is constructed action (CA) or enactment (Cormier et al. 2015), which is a 'showing' strategy as opposed to 'telling' in a narrow linguistic sense (Cuxac 1999). Thus, instances of (S)V(O) or (S)V clauses need to be distinguished from SVO with all core constituents overtly expressed in a clearly linear sequence. Furthermore, as depicting signs in, for example, SOV clauses can occur in a simultaneous construction with core constituents simultaneously expressed, it is important that this type of an apparent SOV clause is differentiated from an SOV clause where each constituent is overtly expressed in sequential order (see Johnston et al. 2007; Hodge 2013). Simultaneous constructions, core argument omission, and varying constituent order has thus made SL researchers question the appropriate 
unit of analysis in constituent order studies. Johnston (2019b: 57), like Hodge (2013), segments SL discourse into clause-like units (CLU) "in recognition of the dual 'tell' or 'show' strategy approach apparently exploited by Auslan signers". These CLUs as the "basic articulatory chunks of propositional meaning" are only units of analysis not to be equated with a "traditional grammatical construction of the type "clause"' (Johnston 2019b: 57). By examining the varying constituent order in simple declarative transitive clauses, clauses with argument omission, and the interplay between CA and a clause in Finnish Sign Language (FinSL), Jantunen (2008; 2013; 2017) concludes that the clause in its traditional sense may not be the most appropriate unit to be used in FinSL. Instead a prosody-based analysis of spoken language syntax where discourse is segmented into syllables and intonation phrases may be more appropriate for the analysis of FinSL syntax (Jantunen 2008).

There has been other work on SLs that has explored the relations between prosody and syntax. Fenlon et al. (2007), for example, found that native British Sign Language (BSL) signers and non-signers perform similarly when segmenting a BSL narrative using visual cues from prosody that help them identify clausal boundaries reliably. Other research on segmentation and prosody drew on work on spoken languages (SpL) claiming that an intonation unit (IU) frequently aligns with a clause. This alignment in cognitive linguistics is attributed to the demands of face-to-face interaction as "the content of a clause fits naturally in a single window of attention" (Langacker 2008: 482). Consequently, there have been studies approaching SL clausal analysis by trying to account for prosodic contours. In one such study on Auslan, Hodge et al. (2011), investigated the alignment of IUs and CLUs. Their findings suggest that a one-to-one alignment between IUs and CLUs is frequently found in the dataset they analysed.

In another study on French Belgian Sign Language (LSFB), Gabarró-López and Meurant (2016) applied the Basic Discourse Unit Model, as proposed for the segmentation of French discourse by Degand and Simon (2009). Gabarró-López and Meurant (2016) proposed that visual prosodic cues, such as eye blinks, short head nods, pauses, and sign holds are important for indicating basic discourse units' boundaries in LSFB. Johnston (1996), however, suggests that individual prosodic features are not cues to CLUs, but that intonation contours which consist of prosodic features that interact with each other are meaningful in Auslan in the sense that they indicate that an utterance is declarative, interrogative, imperative, negative, or conditional. When this suggestion was investigated empirically in a study by Hodge et al. in 2011, it was found that no "absolute functional values" can be attributed to individual prosodic properties within prosodic contours and that it is important to focus on contours rather than boundaries to gauge the interaction between the two (Ferrara 2012: 73-74). Thus, in following corpus studies by Ferrara (2012) and Hodge (2013), CLUs were identified based on a semantic approach, which is underpinned by the presence or absence of intonation contours.

To summarize, in face-to-face discourse, spoken or signed, where utterances are said to be cocreated and negotiated between interactants (Hodge 2013), clause identification is difficult as the identification of factors such as IUs which are found to correspond to single clauses is not as straightforward. The matter of clause delineation is further complicated by factors including simultaneous constructions, and the omission of core arguments.

The previous research on SL constituent order (e.g., Coerts 1994; Hodge 2013; Johnston 2019a) provides the current study with a first working assumption that it is possible to analyse signed utterances from a clause-level perspective. In describing and examining our data, we broadly relied on a cognitive/functional approach while at the same time trying not to force the SL into a (spoken) language model but rather describing it in its own terms (Vermeerbergen 2006). In a functional-typological approach to constituent order, Dryer argues that grammatical relations are unique to every language (Dryer 1997: 140), so the terms subject and object are used in this paper in a semantic sense, equivalent to agent and patient (Dryer 2005: 330). Dryer (1997: 139) further writes that the "similarities among languages can be explained directly in terms of functional and cognitive principles that underlie language and which cause languages to be the way they are". One such cognitive principle is the Gestalt principle of visual perception, that is, the FIGURE-GROUND principle in which people perceive objects as foregrounded (the FIGURE) or as backgrounded (the GROUND). Because locative clauses in SLs depict objects and movements as located in signing space, the analysis of core constituents in a locative clause in terms of grammatical relations is debatable. Instead, it has been suggested that constituent 
order in locative clauses is better described in terms of topic-comment (in ASL for example, Anderson 1978) or FIGURE-GROUND (in Turkish Sign Language or TiD for example, Özyürek et al. 2010). A preliminary study on constituent order in SZJ (Raičević et al. 2017) which included a subset of locative clauses showed that SZJ signers use similar strategies reported for locative clauses in other SLs such as placement and movement of signs in the three-dimensional signing space (Vermeerbergen et al. 2007a; Özyürek et al. 2010; Leeson and Saaed 2012). As these visually more specific ways of linguistic encoding of spatial relations in SLs seem to be more adequately described using the notions of FIGURE, GROUND, and LOCATIVE RELATION (Talmy 2003), we will adopt this terminology in our analysis of locative clauses here.

\section{Previous sign language studies on constituent order}

To date, SZJ, the primary language of the Serbian deaf community, has received little scholarly attention, apart from the preliminary study on basic constituent order in SZJ by Raičević et al. (2017). The findings from that study revealed SVO is the most frequent constituent order in non-locative clauses with two arguments, while the most prominent pattern in locative clauses is GROUND-FIGURE-LOCATIVE RELATION.

Polovina and Dimić (2009) investigated grammatical categories in SZJ through elicited data from an unspecified number of deaf signers and hearing bilinguals whose native languages are SZJ and Serbian. The goal of Polovina and Dimić's study was to determine if there are morphological and syntactic categories in SZJ. Their findings indicate that the clearest example of a morphological category in their data is verbal aspect, and that there is not much evidence of classifier morphemes: "In some sign languages, such as ASL, classifier predicates are mentioned [...], that is, verbs with a handshape that has a classifying function [...]. We did not find any systematic distribution of such classifier morphemes in SZJ" (Polovina \& Dimić 2009: 304; our translation). Another important finding by the authors is that constituent order in many of the clauses is free except in cases when structural ambiguity occurs where constituent order is fixed. Polovina and Dimić (2009: 309) suggest that when it is not possible to distinguish between the roles of the arguments based on the lexical meaning of the signs in a clause, subject before object is obligatory while the position of the verb is free. There is no mention of whether a particular verb type influences constituent order in SZJ. CA and the role of nonmanual markers are not discussed. The difference between clauses in (1a) and (1b) is said to be made on syntactic grounds as Polovina and Dimić (2009) observe that the subject must precede the object. Thus, constituent order as an important coding characteristic may be indicative of grammatical relations in SZJ.

\section{a. MAMA ĆERKA POKLON MUM DAUGHTER GIFT \\ b. POKLON MAMA ĆERKA GIFT MUM DAUGHTER}

'A mother gives a gift to her daughter.' (Polovina \& Dimić 2009: 309)

Napoli and Sutton-Spence (2014) have so far provided the most elaborate typological overview of issues regarding constituent order focusing on subject, object, and verb, drawing on data from 42 SLs. Just as authors before Napoli and Sutton-Spence, namely Johnston et al. (2007) observe, cross-linguistic comparison is difficult because of different data collection methodologies and different definitions of arguments, phrases, and clauses. Some studies rely on more naturalistic data such as free conversations, while others use picture elicitation tasks or translations of SpL clauses (Van Herreweghe \& Vermeerbergen 2012a). The choice of data, however, has been shown to influence constituent order. Engberg-Pedersen (2002), for example, concludes that basic constituent order in clauses with two arguments in DTS is $\mathrm{SVO}^{1}$ or SOV, with SOV possibly being a result of the focusing strategy or a register not influenced by spoken Danish.

Other factors that are claimed to influence constituent order in SLs are the following:

1 Engberg-Pedersen (2002) analysed the arguments in terms of A (the agent in a transitive clause), S (the single argument of an intransitive clause), and $\mathrm{P}$ (the patient in a transitive clause). 


\section{(i) Semantic factors:}

Features such as argument reversibility and animacy also appear to be important (Coerts 1994). Based on investigation of young SLs, emerging SLs, and artificial SL experiments Meir et al. (2017) contend that conceptual accessibility in which humans come first determines the order of introduction of arguments in a transitive clause rather than the arguments' semantic/syntactic role. Therefore, in non-reversible clauses, such as the boy is opening/closing the door the boy is likely to be mentioned first, before the door. While both SVO (e.g., in Croatian Sign Language or HZJ Milković et al. 2006) and SOV (e.g., in Argentine Sign Language or LSA Massone \& Curiel 2004, and Flemish Sign Language or VGT Vermeerbergen 1996) have been reported as the preferred constituent order for non-reversible clauses in a number of SLs, other studies have shown that SOV is less strongly preferred than SVO in reversible clauses (Gibson et al. 2013; Hall et al. 2013; Meir et al. 2017). This is ascribed to ambiguity as both human referents are potential subjects. To avoid confusability speakers/signers tend to separate the arguments by the verb (Gibson et al. 2013) as in SVO. The speaker/signer thus takes into account the interlocutor's perspective and strives to facilitate their comprehension (Hall et al. 2013).

(ii) Discourse-pragmatic factors:

Factors such as topicalization are reported to alter the constituent order in a number of SLs. For example, in LSA it is claimed that the object can precede the subject only if it is topicalized. In such cases, the topic is accompanied by manual and non-manual features typical of the topic, otherwise the order OSV is considered to be ungrammatical (Massone \& Curiel 2004). Johnston and Schembri (2006) explored topicalized constituents in Auslan and non-manual signals associated with them. They conclude that the non-manual signals appear to vary and are not obligatory, perhaps reflecting ongoing grammaticalization processes. A similar claim about ongoing grammaticalization of clause external topics into clause internal subjects is reported for FinSL (Jantunen 2008). In possibly the most thorough study of topic-comment structures in SL linguistics, Sze (2015) investigated frequency and robustness of topic prominence in Hong Kong Sign Language (HKSL) according to the characteristics typical for topic prominent languages as discussed by Li and Thompson (1976) and É. Kiss (1995). Sze (2015) found that the non-manual markers usually associated with topics in the SL literature, such as brow raise or head tilts are not consistent nor frequent in HKSL as is usually the case in topic-prominent SpLs with morphological markers. Finally, Sze (2015: 855) proposes that some presence of a prototypical topic-comment construction, i.e. a double-subject construction ${ }^{2}$ can serve as evidence of topic-prominence in HKSL, but topicalization is not a robust process in HKSL.

Another discourse-pragmatic factor that has been observed to have implications for constituent order is agent backgrounding/defocusing. It has been found in different SLs that a well-attested discourse strategy such as CA may lead to defocusing of the agent by not overtly expressing it. The phenomenon of agent backgrounding/defocusing has most notably been described in ASL (Rankin 2013), FinSL (Nordlund 2019), and Nicaraguan Sign Language (Rissman et al. 2020).

(iii) Iconicity:

It has long been shown that iconicity pervades SL structure, not just in lexical items but also in grammatical structure. Iconicity has been suggested to have an effect on subject drop in German Sign Language (DGS) and Russian Sign Language (RSL) (Oomen \& Kimmelman 2019) where verbs articulated on the body such as LOVE licence non-overt subject argument in first-person interpretation only as the body is the natural locus of first person but also a metaphoric location of loving whereas verbs that are produced in neutral space in front of the signer allow all types of null subjects. The subject drop in DGS and RSL is thus, as the authors suggest, partially constrained due to iconicity. Iconically motivated forms of signs, most notably, depicting signs have been shown to influence argument structure of a clause and its transitivity type. Benedicto and Brentari (2004), for example, propose that the handshape of the sign determines the argument structure. In clauses with handling verb signs the object is usually indicated by 
the sign's handshape and hence not explicitly mentioned often resulting in transitive SV clauses (Meir et al. 2017).

Features that characterise locative clauses, e.g. first-GROUND-then-FIGURE patterns, the use of simultaneous verb constructions to encode the spatial relations between the GROUND and the FIGURE, are associated with iconicity principles (Özyürek et al. 2010). In short, iconicity is a mechanism that helps signers create a schematic correspondence between their hands in the signing space and locations of the real-world entities (Emmorey 1996). The schematic correspondence in SZJ is illustrated in (2a) and (2b). ${ }^{3}$

(2)

a.

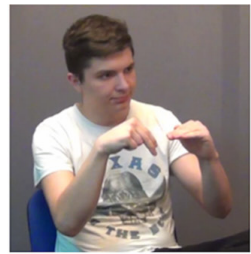

\{RH. DSL(2-DOWN): HUMAN-STANDING; LH. DSL(B-HORI): VEHICLE(Car)-OPPOSITEHUMAN\}

'a person opposite a car'

b.

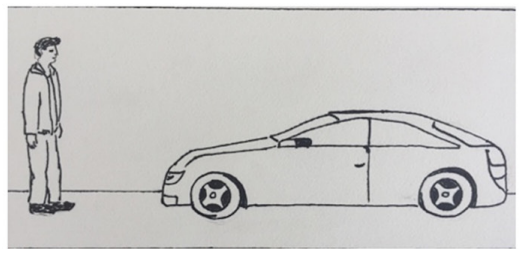

(iv) Modality factors:

Factors that are typical of SLs such as simultaneity, the use of space, and CA may also exert influence on constituent order. Simultaneity is a feature of SLs that distinguishes it from SpLs that mainly order information linearly (Vermeerbergen et al. 2007b). Simultaneous constructions which consist of two simultaneously articulated signs that are placed in space in meaningful reference to each other (Johnston et al. 2007) usually occur clause finally.

The presence of CA and depicting signs has been demonstrated to result in a verb-final order in DTS (Engberg-Pedersen 2002) and VGT (Van Herreweghe \& Vermeerbergen 2012b) However, in a study on VGT and South African Sign Language (SASL) Vermeerbergen et al. (2007a) found that a certain subset of imitating verbs such as HUG and PUSH, and lexical verbs co-occurring with CA do not get placed at the end of the utterance when CA refers to the subject rather than to the object.

Some researchers (e.g., Ferrara \& Johnston 2014) suggest that CA may make null arguments more likely and thus serve as their only representation. Others (e.g., Jantunen 2017), however, do not analyse CA as an instance of a core argument but rather as contributing to the mental construction of the meaning of the non-overt constituent. CA thus adds a level of simultaneity within a clause. In a recent study, Johnston (2019a) states that CA can co-occur with a single sign or with a group of signs in a clause, across an entire clause or even over several clauses. In (3) from SZJ, we see CA occurring with a verb-only clause WASH.

(3)

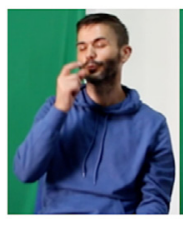

MAN $\mathrm{S}$

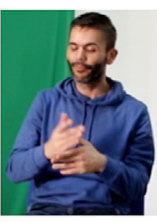

HELP $\mathrm{V}$

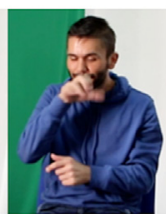

DOG //

$\mathrm{O}$

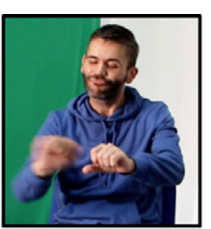

WASH

$\mathrm{V}$

'A man is helping a dog. (He is) washing (the dog)'. 
(v) Verb type and verb modification:

The choice of a verb has been shown to have consequences for the preferred constituent order in different SLs. A tripartite classification of verbs in SLs into plain, agreement and spatial is based on Padden's proposal (1988). Agreement and spatial verbs mark different types of arguments, animate and locative respectively. The meaningful modification of location and movement in agreement verbs can mark person and number and thus resemble inflectional morphemes in SpLs (Padden 1988). However, while a verb such as LOOK has been shown to consistently mark first person object forms on or near the signer's body (see Hou \& Meier 2018 for a study on ASL), it is not always clear if LOOK marks person or location when it is directed outwards and away from the signer (Johnston \& Schembri 2007: 287). This makes the distinction between agreement and spatial verbs problematic. As a result, Liddell (2003) introduced the terms indicating and depicting verbs. Within this framework, studies have reported that there is an interaction between verb position in the clause and the modification of indicating verbs, with verbs in clause final position more likely to exhibit directional alternations (Fenlon et al. 2018). This appears to reflect a general tendency observed in a number of SLs that plain verbs tend to appear in SVO clauses, while modified indicating verbs and depicting verbs tend to occur clause finally. For an overview of verb types and factors that may influence constituent order in some SLs see Table 1 in Appendix.

\subsection{Verbs in SZJ}

In this section, we provide a tentative classification of verbs in SZJ following Johnston and Schembri (2007) who distinguish between plain, indicating, and depicting verbs. Plain verbs cannot be modified to mark person, location or number and are usually body-anchored (Johnston \& Schembri 2007). An example of a plain verb in SZJ is shown in (4).

(4)

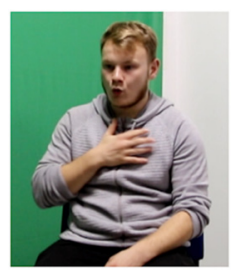

LOVE

Within the indicating verb class a distinction is made between (Johnston and Schembri 2007: 144-146):

(i) Directional indicating verbs that can be modified for the subject and/or the object. WATCH in SZJ in (5), for instance, can usually be modified for object only. Its beginning location is fixed near the signer's eyes. Verbs such as LOOK2 ${ }^{4}$ in (6), on the other hand, can show both the subject and the object.

(5)

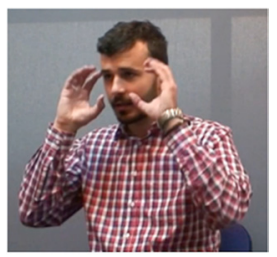

WATCH

(6)

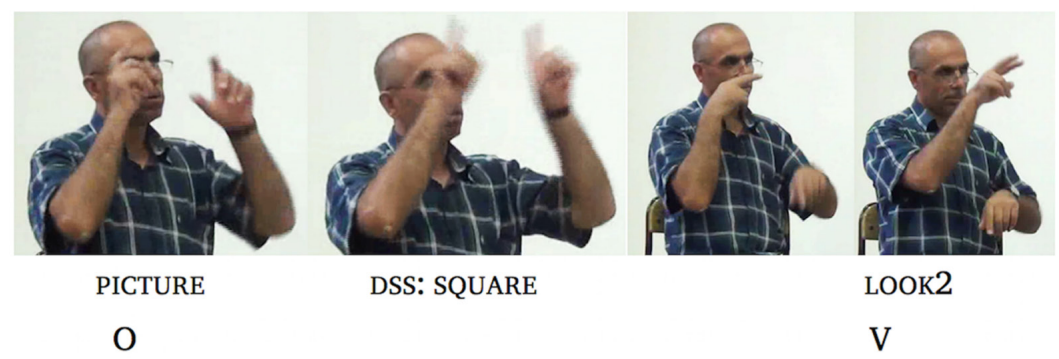

'A picture is being looked at.'

4 We make a distinction between LOOK and LOOK2, in both signs the middle and the index finger extend from the fist, but the palm is oriented either outwards as in (6) or inwards as in (20) and (29). 
(ii) Locatable indicating verbs which can be displaced from their neutral position, i.e. in front of the signer's body to some other location (Johnston and Schembri 2007). Many verbs in SZJ have the potential to be modified meaningfully in this way, e.g. HAVE, SIT, STAND, BUILD, etc. However, very few from our dataset actually were modified, which is why the intuition of the first author, a hearing native SZJ signer, about the potential of the verbs we identified as locatable to be modified was checked against some of the deaf participants' intuition. Another group of locatable verbs primarily signal spatial information, such as TOW or PULL (see 30 or 48) the modification of which can show "the path and trajectory of the sign's motion through space" (Johnston \& Schembri 2007: 145). The so-called "body locating signs", such as STROKE in (7) that include the location on the body where the action is performed also belong to locatable indicating verbs.

(7)

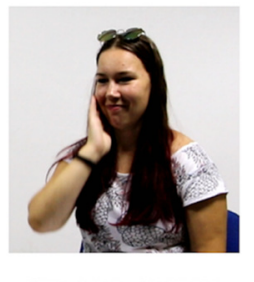

STROKE-CHEEK

Depicting verbs constitute a third major category of verbs in SLs. These signs involve the combination and recombination of meaningful handshapes, movements, and locations, unlike plain and indicating verbs in which all or some aspects of the signs are fixed. Typically, they include what is commonly known as a classifier handshape morpheme (Johnston \& Schembri 2007). After assigning a sign to the depicting (verb) class, a subdivision can be made of depicting signs modified for location (DSL), movement/displacement (DSM), handling (DSH), and size and shape (DSS) (Johnston 2019b). A DSH in SZJ is shown in (8). The same meaning of opening or closing a door in SZJ can be conveyed with a locatable indicating verb in (9).

(8)

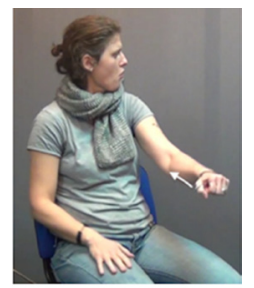

OPEN-DOOR

(9)

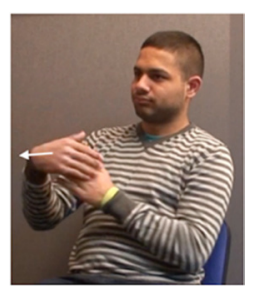

OPEN-DOOR

Based on Johnston (2019b), we also recognised a subclass of CA that can act as a predicate in a clause, such as GROOM-DOG in (10). These are also assigned to the 'depicting verb' grammatical class, as they very much overlap with handling constructions as in (8) which shows the handling of a door knob (see Ferrara 2012 for a discussion on these types of handling constructions).

(10)

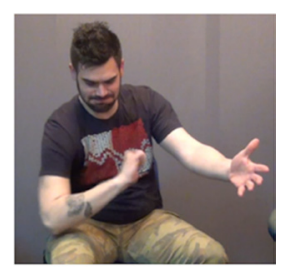

GROOM-DOG 


\section{Research questions}

Based on findings concerning constituent order in other SLs, our research questions include:

What is the most frequent constituent order pattern in our dataset?

- What is the frequency of elliptical clauses?

- How do we determine the transitivity of clauses?

- Do reversibility and animacy exert any influence on the preferred constituent order?

- Do verb type and CA play a role in determining constituent order?

- Do we often encounter simultaneous constructions expressing locative relation in locative clauses? Do they usually occur clause finally?

- Does the first constituent of a clause with a non-manual marker appear in a particular pattern?

- What role do the signer's age, gender, and age of acquisition play in the choice of constituent order in non-locative clauses?

Given the research questions above, we will interpret our findings with respect to four possible analyses: a first analysis that will focus on the simple counts regarding the dataset of nonlocative clauses and locative clauses, a second, third and fourth analysis that will respectively report on (i) quantitative investigations regarding the transitive, intransitive and verb-only non-locative clauses, (ii) the transitive non-locative clauses with one and two overt arguments, and (iii) the transitive clauses with two overt arguments.

\section{Methodology}

\subsection{Participants and data collection}

We collected data from 40 deaf signers. As social factors such as age, age of acquisition, and gender have been shown to play a role in variation in some other SL studies (for the effect of SL exposure on SL use see Emmorey 2002; for the effect of age and gender see Schembri et al. 2009) they were included in the analysis. The classification of our participants into three age groups was mainly made according to the changes in educational policy for deaf students in Serbia (for more information on this and the participants see Appendix). Similar changes have been claimed to have an impact on patterns of use in ASL (Lucas et al. 2001) and BSL (Fenlon et al. 2018).

Clauses were elicited using 18 pairs of drawings from Volterra et al. (1984). Each pair of drawings has one contrastive element, e.g. a boy/girl is eating a slice of cake. There are three kinds of utterances: 6 for non-reversible state-of-affairs, where the order of constituents cannot be reversed without a resultant marked construction arising; 6 for reversible state-of-affairs, where the constituent roles could be reversed; and 6 for locative state-of-affairs, presenting the positions of two elements relative to each other. The Volterra material was created with the intention of eliciting declarative clauses in Italian Sign Language (LIS) in order to investigate constituent order in LIS. Although it has been more than 30 years since this material was used for the first time, this approach lends itself to comparison to other studies on constituent order in SLs that used the same or similar stimuli. It also entails limitations, however, because of the design itself eliciting only semi-naturalistic data. However, we felt it was an important initial step towards exploring an under-investigated SL, SZJ, and a solid basis for comparison to the findings of previous studies (e.g., Coerts 1994; Johnston et al. 2007; Vermeerbergen et al. 2007a), which could be interesting for the documentation of SL diversity in a relatively new field of SL typology.

Sessions included two participants seated across from each other and a deaf research assistant who acted as a mediator (see Figure 1). The procedure for the elicitation task was as follows: the signers had the drawings in front of them. For each pair, one of the drawings was marked with an arrow. The interlocutors, different signers in each case, were looking at the same drawings but in their drawings there was no arrow. The signers were asked to memorise the picture, look away from it and describe what they had seen; the interlocutors were asked to indicate which of the two drawings of each pair was being described. All participants signed an informed consent form which included permission to share videos or images from the sessions for research and teaching purposes. 


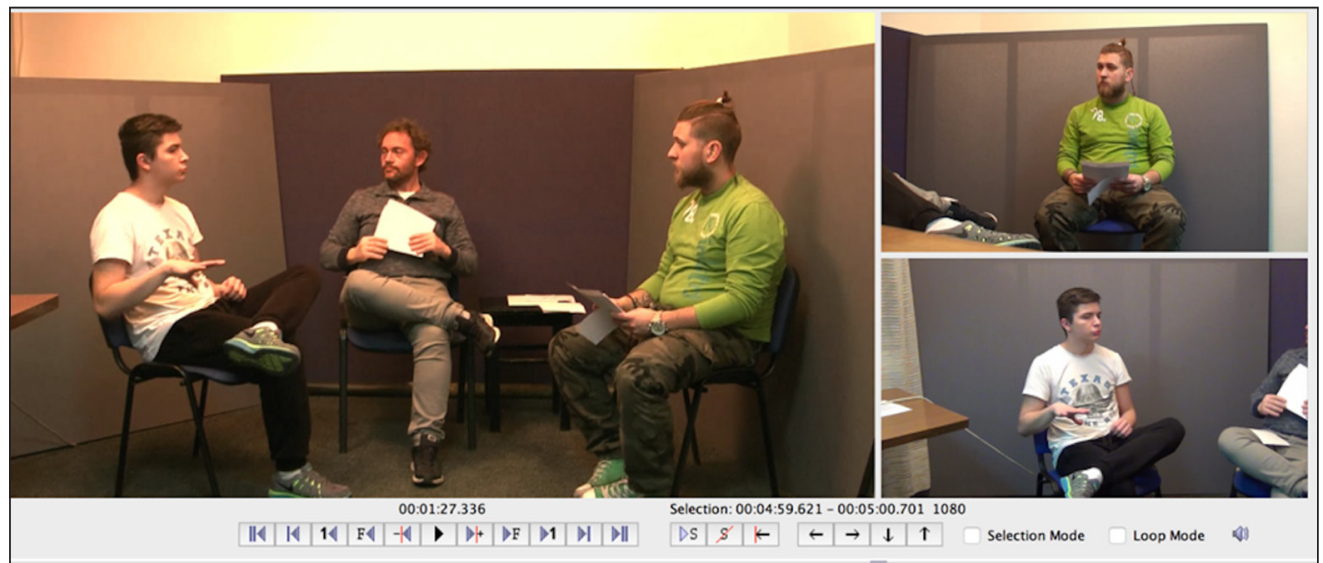

\subsection{Data annotation}

The collected data were annotated in ELAN (Crasborn \& Sloetjes 2008) by the first author of the study who is a hearing native SZJ signer. The tiers that were created for the purposes of this study are outlined in Figure 2. Annotation was carried out across three passes of the data. Clause tier or argument tier annotations, for example, were checked in consultation with deaf and hearing native SZJ signers.

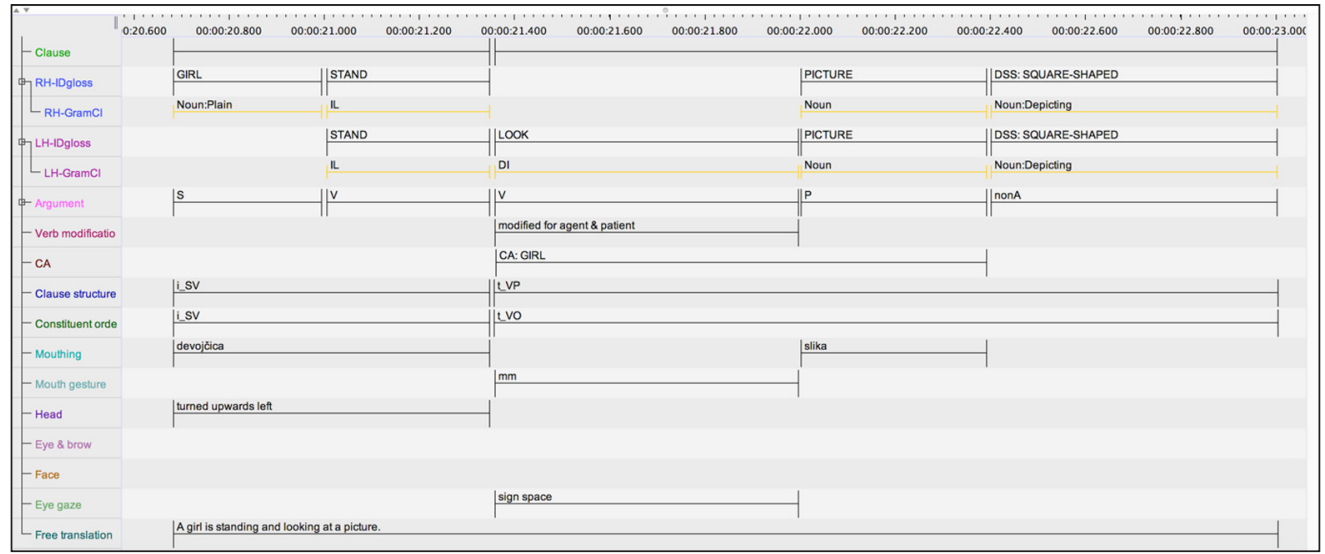

In a first stage of data annotation the signs produced on the right and left hand were assigned ID glosses after which a free translation tier was created. A CA tier was created together with tiers that contained annotations of non-manual features such as head movement, facial expressions, eye and brow, eye gaze, mouth gesture and mouthing. The presence of CA was determined based on the definition of Cormier et al. (2015) who define CA as a mimetic representation of a referent's actions, utterances or emotional reactions. This stage of annotation was completed by an exploratory annotation of clauses on a clause tier.

In a second stage, signs were classified into one of the grammatical classes ${ }^{5}$ mainly based on the Auslan Corpus Guidelines (Johnston 2019b). Particular attention was paid to the classification of verbs as the distinction was made between plain verbs (VP), indicating, and depicting verbs (VD). Depicting verbs were labelled either as VD, or $\{\mathrm{VD}\}$ if both hands were involved simultaneously (cf. Johnston 2019b) as in (11).

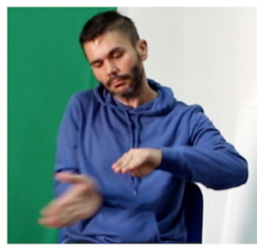

\{RH.DSM(B):TROWEL; LH.DSS(BB): FLAT-SURFACE(brick)\}

'trowel brick'
Raičević Bajić et al. Glossa: a journal of general linguistics DOI: 10.5334 /gjgl.1357

Figure $1 \mathrm{~A}$ snapshot of the layout of the participants in ELAN.

Figure 2 An excerpt from ELAN showing the tiers and data annotation. 
With indicating verbs, we differentiated between directional indicating verbs (DI) and locatable indicating (LI) verbs as already explained in Section 3.1. Similar to Fenlon et al. (2018) DI verbs were judged as unmodified (the form of the verb is the same as its citation form) or modified (the verb is modified for the subject and/or object) on the verb modification tier. As the findings of a corpus-based study on DI verbs in BSL (Fenlon et al. 2018) suggest that modified DI verbs tend to co-occur with CA and occupy clause final position, we wanted to see if the DI verbs in our dataset would echo the findings for BSL. Next, the core arguments were labelled as $\mathrm{S}$ for the single argument of an intransitive clause or A for the agent argument of a transitive clause, and P for the patient argument, while other elements such as adjectives or adverbials were labelled as non-arguments (nonA). Thus, only the heads of noun phrases were tagged on the argument tier (see Ferrara 2012; Johnston 2019a). For example, there were noun sequences in our dataset that usually appear adjacent to each other and designate the same entity. A noun sequence in Figure 2 involves a lexical noun PICTURE followed by a DSS which designates the same semantic structure 'picture', but shows the shape of the picture too. ${ }^{6}$

More information on the order of the verb and its arguments was included on the clause structure tier. This tier captured if a predicate consisted of series of separate verbs labelled as $\mathrm{V} 1, \mathrm{~V} 2, \mathrm{~V} 3$, etc. as in (12).

$\begin{array}{lllll} & \text { WORKER } & \text { MAKE } & \text { BUILD } & \text { HOUSE } \\ \text { Clause structure } & \text { A } & \text { V1 } & \text { V2 } & \text { P } \\ \text { Constituent order } & \text { S } & & \text { V } & \text { O }\end{array}$

'A worker is making, building a house.

To identify such a serial verb the following criteria must be satisfied: the verbs share the same subject, the verbs are formed as one phonological unit, and the verbs are used within the same intonation contour (Johnston 2019b: 74). MAKE and BUILD in (12) would represent a case of a serial verb in SZJ. A simultaneous verb construction labelled as $\{\mathrm{VD}\}$ on the grammatical class tier, which usually consisted of two depicting signs, was labelled as $\{\mathrm{V}\}$ on a clause structure tier. The clause structure tier summarized the order of arguments and verb in terms of A/S, P, $\mathrm{V}$ or $\{\mathrm{V}\}$.

In a third stage, we revisited the annotation of clauses and coded the constituent order in terms of subject (S), object $(\mathrm{O})$ and verb (V) on a constituent order tier (see Figure 2). This was done due to recognisability with respect to the six-way word order typology (Dryer 2005). ${ }^{7}$ The annotation of all predicates that consisted of a series of verbs or two simultaneously articulated signs was simplified on the constituent order tier as V.

For the locative state-of-affairs we decided to focus on the locative relation, and use labels GROUND and FIGURE (Talmy 1975). We also included information on simultaneity, nonmanual marking, and the use of space. Spatial relations between entities are labelled as LOCATIVE RELATION. LOCATIVE RELATION was often expressed by a construction consisting of two signs placed into the signing space either simultaneously or sequentially. In our data, this type of sequentiality involves part of one sign perseverating on the non-dominant hand as a fragment buoy (FBUOY) while the dominant hand is used to articulate a lexical sign, followed by a depicting sign, as in (13) which is coded as GROUND-FIGURE-LOCATIVE RELATION.

$$
\begin{array}{ll}
\text { VASE }\{\text { LH.FBUOY: VASE } & \text { RH: FLOWER, RH.DSH: } \left.{ }_{1 \mathrm{fICK}} \text { PICU-AND-MOVE }{ }_{\mathrm{rt}}\right\} \\
\text { GROUND } & \text { FIGURE }
\end{array}
$$

'Flowers are picked up and moved from a vase.'

The annotated data were exported as .csv file into an Excel spreadsheet. The spreadsheet containing non-locative data was further exported as .txt file and used for statistical analysis.

\footnotetext{
6 This DSs can also be analysed as a predicate. In our analysis, however, it was treated as an attributive occurring after a noun and before a noun.

7 The six logically possible orders, from the widely attested to the rarest, are SOV, SVO, VSO, VOS, OVS, and OSV (Dryer 2005).
} 


\subsubsection{Defining and delineating a clause}

The clause is the basic unit of our analysis as it is generally considered to be the primary syntactic domain in typological studies on constituent order (Dryer 2005: 330). In this paper, we are interested in constituent order in single clauses, i.e. "stand-alone utterances that are not overtly linked to or embedded in another clause" (Johnston 2019a: 955). However, sometimes we were presented with an integrated response consisting of an intransitive and a transitive clause, or an intransitive clause only that described the state-of-affairs depicted. We decided to analyse such responses even though reversible and non-reversible states-of-affairs are by definition transitive events. To demarcate clausal boundaries, we focused on a predicating element which together with its arguments constitute the core of a clause while other elements, such as locative and temporal items are the periphery of a clause (Johnston \& Schembri 2006).

Prosody was another factor relied upon in determining the constituents and the boundary of the clause (cf. Fenlon et al. 2007). Similar to Jantunen (2008), a declarative clause is considered to be a single prosodic unit if there are no pauses between the different constituents of the clause. A pause was interpreted as "such period of time where the articulator remains immobile for at least eight hundreds of a second" (Jantunen 2008: 88). If, however, there is a nonmanual marker such as a head nod, a squint or simply a pause that might suggest that the first constituent is topicalized, this structure was tagged as top (see Johnston 2019a), as in (14).

$$
\begin{array}{llll}
\multicolumn{4}{c}{\text { nod }} \\
& \text { MAN } \quad \text { WASH }_{\text {self }} \quad \text { DOG DSS: DOG-THIS-HIGH } \\
\text { top_t } & \mathrm{S} \quad \mathrm{V} & \mathrm{O} \\
& \text { 'A man is washing a dog this high.' }
\end{array}
$$

This kind of tagging was used to see if any particular order of constituents co-occurred with the presence of non-manual marking on the first constituent.

\subsubsection{Clause transitivity}

Apart from a top tag, the information on transitivity of clauses with at least one overt argument was also included, i.e. clauses were labelled as $t$ for transitive or $i$ for intransitive. Both transitivity type and topicality were marked on the clause structure and constituent order tier (see Figure 2).

Transitivity is regarded as a scalar phenomenon (Thompson \& Hopper 2001; Börstell et al. 2019). As Thompson and Hopper (2001) observe transitivity is a property of the grammar of the clause as much as of the verb. To identify a prototypically transitive clause a number of parameters have to be met (Thompson \& Hopper 2001) such as the presence of two participants, highly potent agent, highly affected and individuated object, the presence of a volitional affirmative telic verb, etc. The annotation of clauses quickly revealed that argument omission encumbers the identification of transitivity. In elliptical clauses with ambitransitive verbs we relied on context for determining transitivity. For example, (15) was analysed as intransitive even though one may argue that the orientation and location of the verb, i.e. a handshape oriented forward with up-and-down movements imitating the strokes of a hand as if holding a brush against a vertical surface may imply a wall shown in the stimulus. However, the exact same parameters of the sign (location at which it is directed, movement, handshape) appear in its citation form. Therefore, as there were no contextual cues that may have suggested an object more explicitly, we decided to classify the clause as intransitive. On the other hand, examples such as (16) were analysed as transitive as the object 'cheek' was analysed as being more clearly implied in the form of the verb.

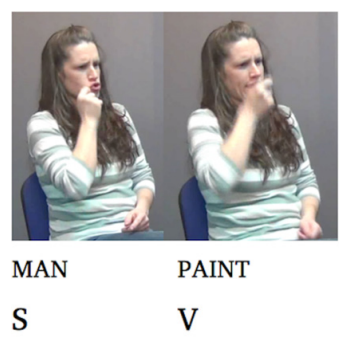

'A man is painting.' 
(16)

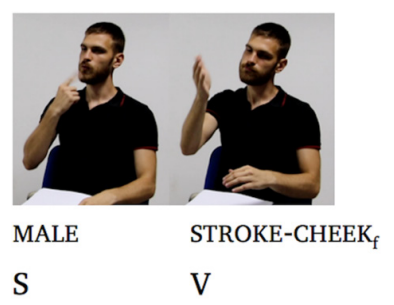

'A man is stroking (a girl's) cheek.

As the main goal of our study is to determine the position of a verb with respect to its overt argument(s), we did not tag verb-only clauses for transitivity. Such an approach has implications for patterns extracted to which we turn in Section 7.3.

\subsubsection{Some issues with data annotation and analysis}

The annotating process and data analysis were challenging, particularly with respect to depicting signs, multi-clausal strings, repetition of verbs, and juxtaposition of signs.

The classification of depicting signs in some instances was difficult. While all DSM and DSH were tagged as verbs and all DSS as nominals, the decision regarding DSL was not as clear-cut. Several clauses with DSL occurring after a noun had possible alternate interpretations. While it is indisputable that DSL attributes a location to an entity, the exact meaning of DSL which can either be interpreted as an element within a nominal phrase, as an argument or as a verb, is not always clear. In a first interpretation of (17), DSL: VEHICLE functions as an adjunct in a nominal phrase, attributing a location to the previously introduced noun TRUCK ('a truck at that place is followed by a car') resulting in SOV. In a second interpretation, DSL is an argument functioning as an attribute in an attributive clause 'a truck (is) here//a car is following the truck'. In a third interpretation, DSL is analysed as a locative verb 'a truck is sitting here//a car is following the truck', which would mean there are two SV clauses. In a fourth interpretation, DSL can be analysed as representing a complete state-of-affairs and a clause in its own right (see Liddell 2003; Johnston 2019b). In this analysis, DSL is interpreted as a modifying clause embedded into the matrix clause 'a truck that is located here is being followed by a car'. In our analysis, (17) is interpreted as an SOV? clause. A question mark on the dedicated constituent order tier, after a constituent string in question indicates that this particular analysis requires further attention.

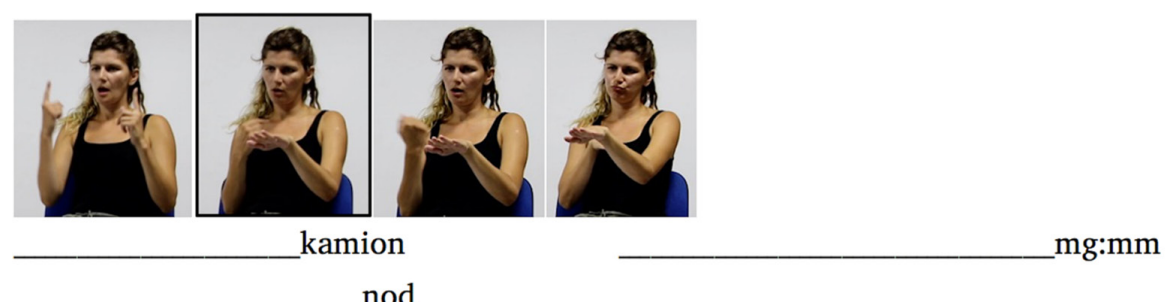

nnod

TRUCK $\quad$ LH: DSL(B- $\quad$ LLH: DSL(B- $\quad$ \{RH: DSM(B-HORI): VEHICLE-AT-LOC ${ }_{\mathrm{c}}$-MOVE; LH: HORI): $\quad$ HORI(truck) DSM(B-HORI): VEHICLE-AT-LOC $f^{-}$MOVE $\}$

VEHICLE ; RH. FBUOY:

(truck) CAR

$S$

$\mathrm{O}$

$\mathrm{V}$

?

'A truck is moving in front of a car.'

Whether DSL is best analysed as a non-core modifying element within a nominal phrase, a core constituent of a clause or an embedded modifying clause requires further evidence. While the rightward spreading behaviour of the mouthing kamion 'truck' prosodically binds the first argument TRUCK to the adjacent VEHICLE (Boyes Braem 2001), it is not entirely clear whether the two signs are forming a phrase or a clause. Similarly, a pause and a nod after DSL may serve as an indication of a clausal or a phrasal boundary. However, the strongest argument for analysing (17) as one clause was found in the perseveration of the sign on the non-dominant left hand, which makes (17) resemble one unit in delivery. 
Examples with SIT and STAND (see 18) also posed challenges for data annotation and analysis. It has been suggested in literature (see Johnston et al. 2007) that SIT and STAND can be analysed as modifying adjectives ('seated girl'), as part of relative clauses ('a girl who is sitting') or as attributing a spatial locus to an entity as suggested for some instances in VGT (Van Herreweghe \& Vermeerbergen 2012b).

$\begin{array}{lllll}\text { GIRL } & \text { SIT } & / / & \text { WATCH } & \text { TV } \\ \text { S } & \text { V } & & \text { V } & \text { O }\end{array}$

'A girl is sitting (and) watching TV.'

We analysed examples such as (18) as two clauses because there is no evidence to suggest that they are a particular type of serial verb or multiverb clause construction, and - pending such evidence - we felt it is best to treat them as separate clauses while also acknowledging that they might form some kind of a serial verb construction. Unlike Johnston et al. we did find with most of the examples such as (18) a systematic pattern of pauses occurring after SIT or STAND; but, similar to Johnston et al. (2007) in none of the examples except one did we find a conjunction.

Another sign sequence that appears in the data involves a 'verb sandwich' construction (Fischer \& Janis 1990) in which the verb is repeated after the object in the same or modified form, as in (19).

$$
\begin{array}{llll}
\text { GRANDMA } & \text { HUG } & \text { GRANDCHILD } & \text { HUG } \\
\text { S } & \text { V } & \text { O } & \text { V }
\end{array}
$$

'A grandma is hugging a grandchild.'

As these examples occurred within the same prosodic contour and resembled a single clause in delivery, we decided to treat them as single clauses (see Van Herreweghe \& Vermeerbergen 2012b). Additional reason for treating these strings as single clauses was the use of CA with both verbs, namely if the first verb co-occurred with CA so did the second. Whether SVOV is a distinctive type of constituent order typical of SLs as implied by Johnston et al. (2007) awaits further research.

It is interesting to note that two signers produced three clauses with two signs juxtaposed, e.g. CAR DIRTY. Here, we decided to treat both constituents as arguments and the utterances as verbless attributive clauses, but we recognise that it is difficult to know for certain whether the sign glossed here as DIRTY is an adjective or a verb (i.e., BE-DIRTY). Any decision on what counts as a predicate and an argument has an impact on the patterns extracted from the data (see Ferrara 2012). The clauses above could have been tagged as SV and as such would have increased the SV pattern by two. However, these attributive clauses were not included in the analysis.

\section{Findings}

The number of analysed clauses is 810 . Approximately two-thirds of the time, participants produced single clause responses while in the remaining one-third the participants' responses were multi-clausal. We analysed 338 (42\%) clauses for the non-reversible state-of-affairs, 272 (33\%) for the reversible state-of-affairs and 200 (25\%) for the locative state-of-affairs (see Figures 3 and 4). There were twelve singular responses ${ }^{8}$ for the locative state-of-affairs that were excluded from the analysis. Furthermore, clauses elicited for locative state-of-affairs that had verbs such as EMPTY, SIT, HAVE, etc. were not considered for the purposes of this study as they did not seem to provide spatial or locative information.

A total of 409 (50\%) declarative transitive clauses, 76 (9\%) intransitive clauses, 125 (15\%) verb-only, and 200 (25\%) locative clauses constitute the dataset of this study. Of 610 nonlocative clauses, 325 (53\%) had both arguments overtly expressed, 84 (14\%) were transitive clauses with one overt argument, 76 (13\%) were intransitive clauses while $125(20 \%)$ were verb-only clauses.

8 For example, there was only one pattern of FIGURE-DSL-LOCATIVE RELATION-GROUND (e.g., TREE DSL:VERTICAL-ENTITY ${ }_{\mathrm{F}}$ BACK HOUSE) that could not be grouped with the other 15 patterns that contained at least two examples produced by different signers. 

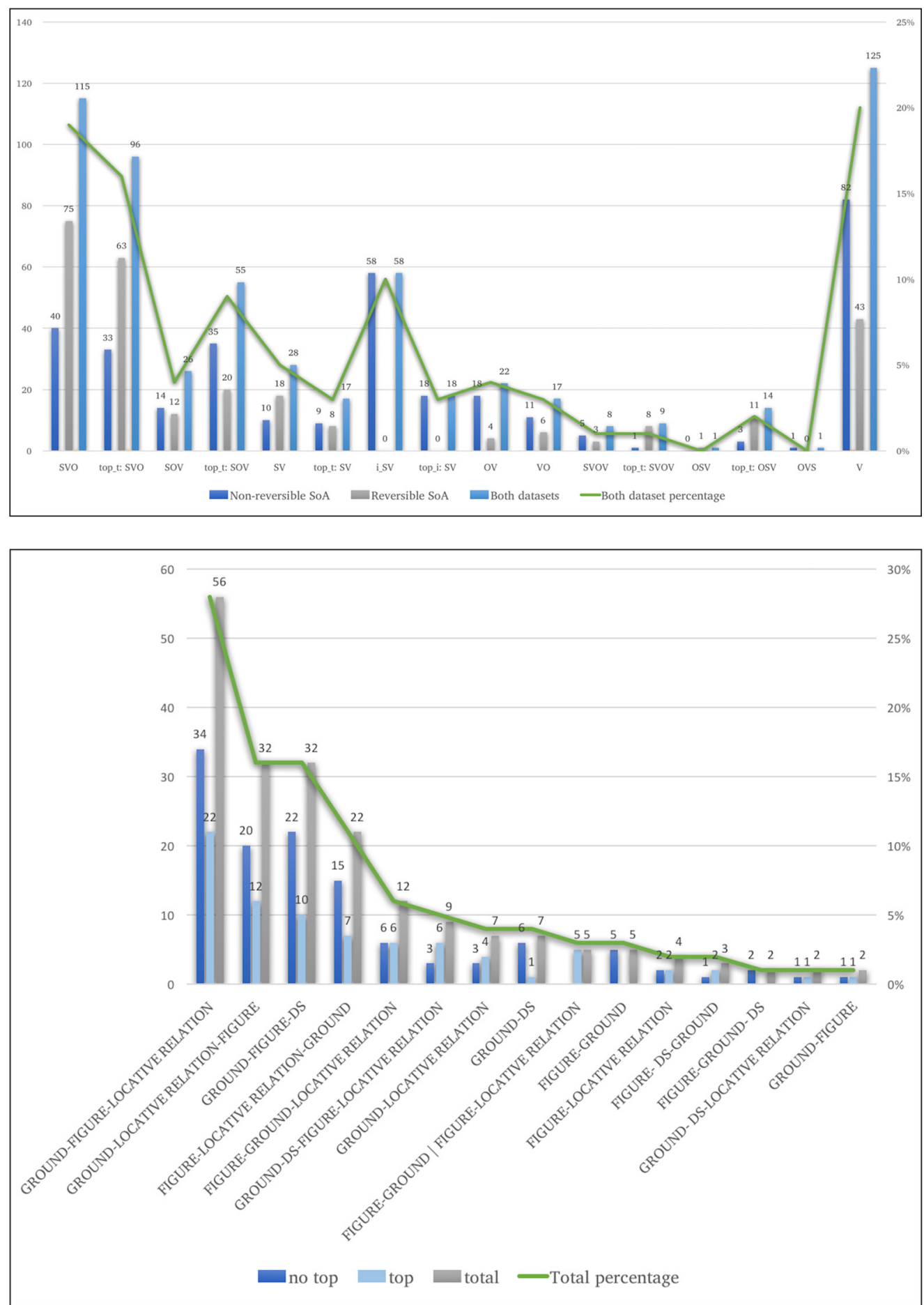

In the following subsections, we present an overview of the findings on constituent order, and constituent order and verb type for each state-of-affairs separately. Section 7 provides a summary of the main findings, and links the findings to the research questions. The diverse nature of constituents and relations between them is addressed in Section 8, followed by a conclusion.

\subsection{Non-reversible state-of-affairs}

\subsubsection{Constituent order}

For non-reversible state-of-affairs, we analysed 180 (53\%) transitive clauses, 86 (25\%) of these 180 have a topic-like constituent (top_t). We also identified $76(22 \%)$ intransitive clauses (e.g., MAN SIT) of which $18(5 \%)$ are topicalized, and 82 (25\%) verb-only clauses (e.g., PAINT). The most frequent constituent order is SV, followed by verb-only, SVO, SOV, OV, VO, SVOV, OSV, and OVS (see Figure 3).

When looking at transitive clauses alone, SVO (see 20) is the most frequent order followed by SOV (see 21) and SV. Most of the SV transitive clauses contain a predicate in which the object seems to be implied by handling as in (22).
Figure 3 Constituent order in non-locative clauses.

Figure 4 Elicited patterns for locative state-of-affairs. 
(20)

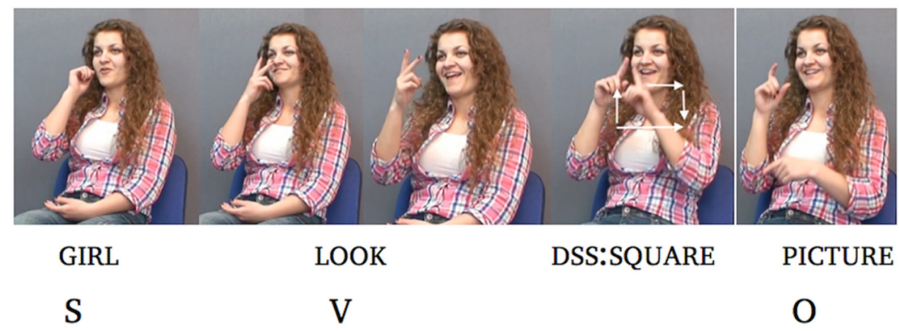

'A girl is looking at a painting'.

(21)

MAN CAKE DSH: CUT-SLICE

S O V

'A man is cutting a slice of cake.'

(22)

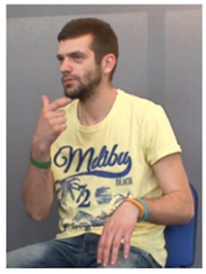

EAT-SLICE-OF-CAKE

In the majority of the SVO clauses, the explicit mentioning of the arguments and no topicalization seem to suggest that SVO could be the most neutral way of expressing a transitive state-ofaffairs. Conversely, the majority of the SOV clauses had a first constituent topicalized.

In clauses with the omitted subject, we identified an OV pattern (see 23) and a VO pattern. All of the VO clauses were produced as part of a multi-clausal response, after another clause (see 24).

TV WATCH

O V

'TV is being watched.'

MAN SIT $\mid / / \quad$ LOOK2 PICTURE

$\begin{array}{llll}\mathrm{S} & \mathrm{V} & \mathrm{V} & \mathrm{O}\end{array}$

'A man is sitting (and) looking at a picture.'

Besides VO and OV, verb-only clauses also occurred mostly as part of a multi-clausal sequence. Overall, looking at the clauses with omitted arguments (e.g., SV, VO, OV, and verb-only), almost half of the responses, 100 of 206 , were multi-clausal.

We also identified six instances of SVOV, with the second verb modified for aspect (see 25) or repeated in the exact same form as the first verb. Three clauses were OSV (see 26), all three with the first constituent topicalized. One clause was OVS (see 27), but this clause was produced right after SVO, and served to further clarify the event in the picture and could therefore be analysed as a marked construction.

$$
\begin{array}{llll}
\text { GIRL } & \text { WATCH } & \text { TV } & \text { WATCH + } \\
\text { S } & \text { V } & \text { O } & \text { V }
\end{array}
$$

'A girl is watching TV.'

$$
\begin{array}{lll}
\text { STRING } & \text { YOUNG-MAN } & \text { CUT-WITH-SCISSORS } \\
\mathrm{O} & \mathrm{S} & \mathrm{V}
\end{array}
$$

'A young man is cutting a string with scissors.'

$$
\begin{array}{llllll}
\text { GIRL } & \text { LOOK2 } & \text { PAINTING // } & \text { DSS: SHAPES } & \text { LOOK2 } & \text { GIRL } \\
\mathrm{S} & \mathrm{V} & \mathrm{O} & \mathrm{O} & \mathrm{V} & \mathrm{S}
\end{array}
$$

'A girl is looking at a painting. A girl is looking at shapes.' 


\subsubsection{Verb types in non-reversible state-of-affairs}

In our dataset of non-reversible state-of-affairs, there are 354 verb tokens. Table 2 (see Appendix) shows constituent order based on verb type. The table includes information on CA, modification of DI verbs and simultaneity. Thus, for instance, we observe that 22 of 38 VDs that appear in SOV are a simultaneous construction. Another observation concerning VDs is that they occur most frequently in verb final transitive clauses (i.e., SOV, SV, OV, and OSV), except 3 instances that occurred clause medially in SVO as in (28) All other verb types favour SVO.

(28)

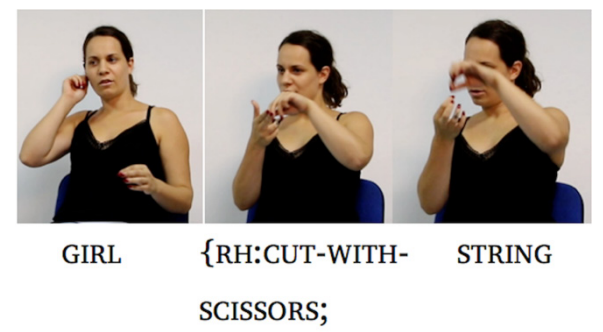

LH.DSH(F):HOLD
-STRING

$\mathrm{S} \quad \mathrm{V}$

A girl is cutting a string.

The most frequent LI verb type appeared most often in intransitive SV clauses. It was also the dominant verb type in the SVO and verb-only clauses. DI verbs appeared most often in SVO. Overall, 32 of 52 instances of DI verbs were judged as modified (see 29), and 20 as unmodified (see 20).

(29)

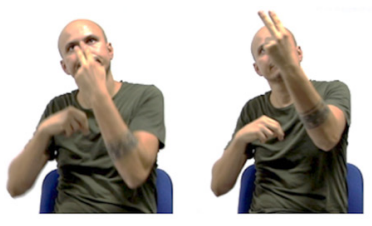

LOOK

V

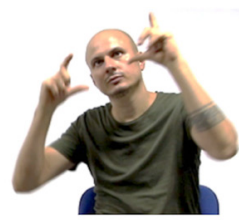

PICTURE

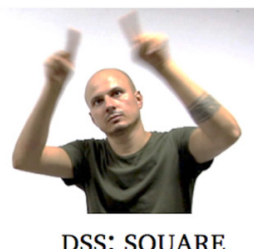

DSS: SQUARE
$\mathrm{O}$
Raičević Bajić et al. Glossa: a journal of general linguistics DOI: 10.5334 /gjgl.1357

'(A girl) is looking at a painting'.

Finally, there were 23 instances (44\%) of CA co-occurring with DI verbs (see Table 3 in Appendix), 22 were modified, while 1 was unmodified. In fact, of the 28 modified DI verbs 22 were used with CA.

\subsection{Reversible state-of-affairs}

\subsubsection{Constituent order}

The most frequent order in clauses for reversible state-of-affairs is SVO (see Figure 3), as in (30), with 138 tokens (51\%). Looking at clauses with two overt core arguments, the second most frequent pattern is SOV. Most of the SOV clauses have a topicalized first constituent, as in (31). Another pattern with two overt core arguments is OSV, with 11 of 12 clauses having a topicalized first constituent, as in (32).

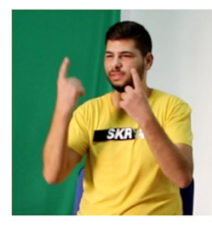

TRUCK

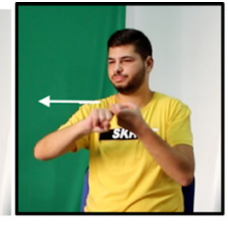

TOW

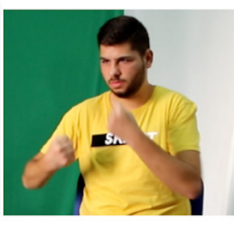

CAR

'A truck is towing a car.' 
(31)

\begin{tabular}{llll}
\multicolumn{4}{c}{ _nod } \\
top_t & GIRL & BOY $\quad$ COMB & \\
& & 'A girl is combing a boy's hair.' \\
& & & CA: BOY \\
& GRANDMA & BOY HUG \\
top_t & O & S & V \\
& 'A boy is hugging a grandma.'
\end{tabular}

We also identified SVOV clauses. Five of the 11 SVOV clauses featured verbs such as STROKECHEEK, which can be signed on the signer (STROKE-CHEEK ${ }_{\text {self }}$ ) or in front of the signer's body (STROKE-CHEEK $\mathrm{f}_{\mathrm{f}}$, as in (33). Morgan et al. (2002: 662) call these "AB verb constructions". They encode a two-participant event with the signer articulating the main verb from two perspectives, the first one that specifies the subject and the action 'a girl strokes cheek', and the second one that specifies the object, the action, and the body part involved 'stroke a boy's cheek'.

$$
\begin{array}{llll}
\text { GIRL } & \text { STROKE-CHEEK }_{\mathrm{f}} & \text { BOY } & \text { STROKE-CHEEK }_{\text {self }} \\
\mathrm{S} & \mathrm{V} & \mathrm{O} & \mathrm{V}
\end{array}
$$

'A girl is stroking a boy's cheek.'

We also identified a set of SV clauses but did not find a VS pattern. Apart from the transitive SV, VO and OV were two other patterns with only one overt argument. All VO clauses followed another clause, as in (34).

$$
\begin{aligned}
& \text { _nod } \\
& \text { TRUCK TOW } \mid / / \text { TOW SUPERB CAR DSS.FLATBC: ELONGATED-VEHICLE } \\
& \begin{array}{llll}
\mathrm{S} & \mathrm{V} & \mathrm{V} & \mathrm{O}
\end{array}
\end{aligned}
$$

'A truck is towing a superb sleek car.'

In a number of verb-only clauses we observed an agent defocusing strategy with the subject not overtly expressed but represented through CA. All of these verb-only clauses were produced in a continuation of another clause, as in (35).

(35)

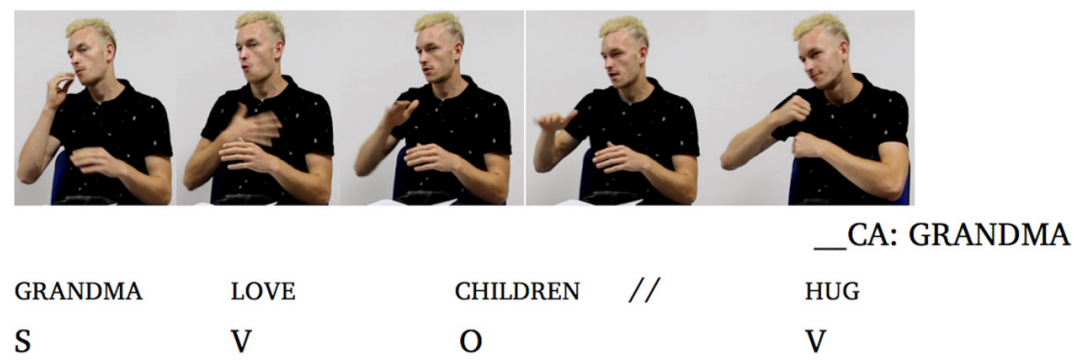

'Grandmother loves children. (She) hugs (them).'

\subsubsection{Verb types in reversible state-of-affairs}

There are 283 verb tokens in clauses describing reversible state-of-affairs. For an overview of constituent order in relation to verb type see Table 4 in Appendix.

The most common verb type was LI. It appeared most frequently in SVO (see 30). The second most frequent verb type in reversible state-of-affairs was DI. DIs occurred predominantly in SVO - 50 instances, 21 of which were the verb PUSH that was always used in its unmodified form, except once when it was modified (see 36). We also identified three instances of VPs appearing in SVO, as in (35). 
(36)

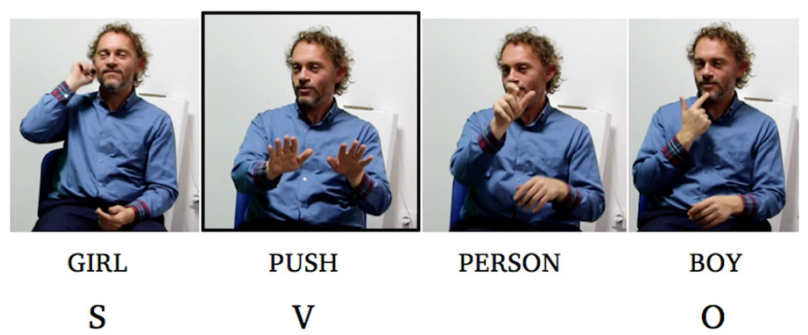

'A girl is pushing a boy.'

All verb types in reversible state-of-affairs, except VDs, favour SVO. VDs occurred most frequently in verb final and verb-only clauses. Most of VDs in verb-only clauses, all of which were produced after another clause, were simultaneous verb constructions (see 37). VDs are the only verb type that co-occurred with CA in the majority of cases as can be seen in Table 5 in Appendix.

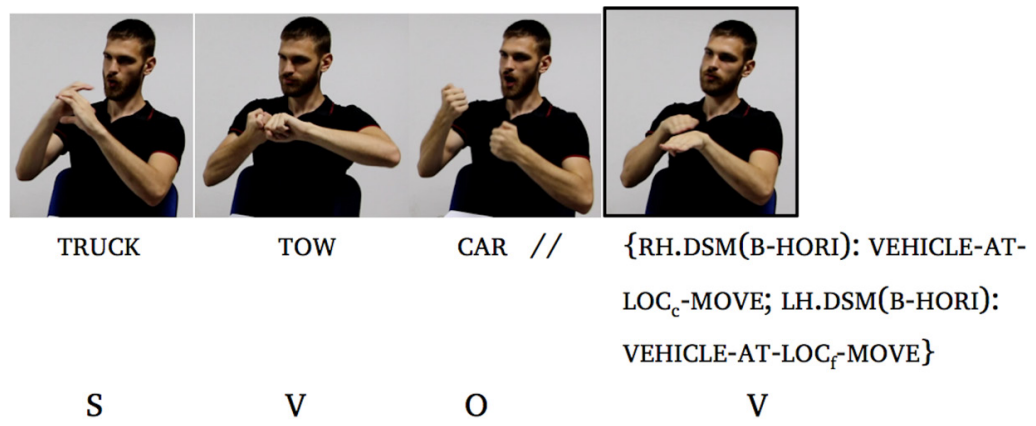

'A truck is towing a car. They are moving one after the other.'

\subsection{Multivariate analysis}

Given previous claims in the SL linguistics literature that linguistic factors such as reversibility, verb type, and CA can influence constituent order in different SLs, we decided to investigate the effect of these factors in SZJ quantitatively. Furthermore, we tested for topicality to see if a particular pattern favours topicalized initial constituents. As we also wanted to determine the effect of social factors, such as the signer's age, age of acquisition, and gender, these factors were included in the analysis.

We used a mixed effects model in Rbrul (Johnson 2009) to determine the effect of the linguistic and social factors on a binary linguistic variable i.e. whether the target was SVO or 'other', with participant as a random effect and all other predictors as fixed effects. Both log odds and factor weights are used to report results in Rbrul. A positive log odd result, or a factor weight between .50 and 1.00 means that this particular factor 'favours' the use of SVO, while a negative log odd result, or a factor weight between 0 and .50 means that SVO is less likely to occur (Tagliamonte 2006). Log odds and factor weights should be considered with respect to other log odds and factor weights within each category, e.g. a higher factor weight for DI verbs and a lower factor weight for LI verbs means that DI verbs favour SVO compared to LI verbs. Furthermore, a log odd close to 0 or a factor weight close to .50 may be interpreted as being neutral concerning SVO. It is also important to note that Rbrul tests the significance of each factor on the use of the target, and the relative strength of the influence each factor has when compared to other factors (cf. Fenlon et al. 2018).

As Rbrul requires a binary dependent variable, we had to group the data together into binary sets. For the first analysis, we collapsed all transitive clauses with at least one overt argument with the subject occupying clause initial position and the object clause final position into (S) $\mathrm{V}(\mathrm{O})$, while all other patterns were labelled as 'other' (see Table 6 in Appendix). To be able to draw a more accurate comparison with similar studies that focused mainly on declarative transitive clauses with at least one overt argument, we conducted a second analysis from which we excluded intransitive clauses, SVOV and verb-only clauses. Again, the dependent variable had two values $(\mathrm{S}) \mathrm{V}(\mathrm{O})$ and 'other' (see Table 7). The second analysis was based on a reduced dataset of 392 tokens from 610 tokens. In a final analysis, we included declarative transitive clauses with two overt arguments (308 tokens from 392), that is, SVO versus SOV, OSV and 
OVS which we collapsed into 'other' (see Table 8). The purpose of the third analysis was to verify whether the factors that appeared to be significant in the second analysis remained significant in the third analysis.

\subsubsection{The influence of linguistic and social factors on constituent order in non- locative clauses}

In Table 9 (see Appendix), which shows the results for 610 non-locative clauses three factor groups were found to be significant in predicting $(\mathrm{S}) \mathrm{V}(\mathrm{O})$ : verb type $(\mathrm{p}<0.0001)$, reversibility ( $\mathrm{p}<0.0001)$ and topicality $(\mathrm{p}<0.05)$. For verb type, DI (1.093) and LI $(0.220)$ verbs were the factor that favoured $(\mathrm{S}) \mathrm{V}(\mathrm{O})$ while VPs $(-0.605)$, and VDs $(-0.707)$ disfavoured $(\mathrm{S}) \mathrm{V}(\mathrm{O})$. The second factor that was found to be significant in predicting $(\mathrm{S}) \mathrm{V}(\mathrm{O})$ was reversibility. Reversible tokens favoured ( $) \mathrm{V}(\mathrm{O})$ (0.586) compared to non-reversible tokens $(-0.586)$. The third factor was topicality. Here, clauses with an initial topicalized constituent were more likely to be $(\mathrm{S}) \mathrm{V}(\mathrm{O})$ than clauses that had no non-manual marking on the first constituent. Finally, we found the social category of gender $(\mathrm{p}<0.02)$ to play a significant role in predicting $(\mathrm{S}) \mathrm{V}(\mathrm{O})$ (see Table 10 in Appendix). More specifically, women favoured (S)V(O) (0.328) compared to men $(-0.328)$.

In the second analysis based on transitive clauses with at least one overt argument (392 tokens) verb type ( $p<0.0001)$, and topicality ( $p<0.01$ ) were again found to be significant while reversibility $(\mathrm{p}>0.3)$ and CA $(\mathrm{p}>0.05)$ were not significant (see Table 11 in Appendix). For verb type, DI verbs favoured $(\mathrm{S}) \mathrm{V}(\mathrm{O})(0.728)$, followed by LI verbs (0.626) and VPs (0.229) while VDs disfavoured $(\mathrm{S}) \mathrm{V}(\mathrm{O})(-1.583)$. Within the category of topicality, we see that the absence of non-manual marker on the first clausal constituent favoured (S)V(O) (0.374). Table 12 (see Appendix) shows the categories of gender $(\mathrm{p}<0.005)$ and age $(\mathrm{p}<0.05)$ to be significant, with women $(0.454)$ and the youngest signers $(0.596)$ favouring $(\mathrm{S}) \mathrm{V}(\mathrm{O})$.

The third analysis based on transitive clauses with two overt arguments revealed verb type ( $\mathrm{p}<0.0001$ ), topicality ( $\mathrm{p}<0.005$ ), and CA $(\mathrm{p}<0.05)$ to be significant. Table 13 (see Appendix) shows that VPs strongly favoured SVO (12.907), while all other verb types disfavoured SVO. With respect to topicality, the results of the second analysis were confirmed i.e. no nonmanual marker on the initial constituent favoured SVO (0.594). Similarly, reversibility was not significant as in the previous analysis. However, compared to the second analysis where CA was not significant, it was found to be significant in the third analysis ( $p<0.05$ ), with no CA favouring SVO (0.594). Gender ( $\mathrm{p}<0.001)$ and age group $(\mathrm{p}<0.05)$ remained significant like in the second analysis with women (0.535) and the youngest signers $(0.793)$ favouring SVO (see Table 14 in Appendix).

All three analyses found the categories of verb type and topicality to be significant in predicting $(\mathrm{S}) \mathrm{V}(\mathrm{O}) / \mathrm{SVO}$. Within the verb type category, the first analysis revealed DI and IL verbs to favour $(\mathrm{S}) \mathrm{V}(\mathrm{O})$, the second analysis showed DI verbs, LI verbs, and VPs to favour (S)V(O), while the third analysis found VPs to favour SVO most strongly. VDs disfavoured (S)V(O) in all analyses. Regarding topicality, the results of the first analysis differed compared to the second and third insofar as they showed that the presence of the initial topicalized constituent favoured (S)V(O). However, if we focus more closely on the result of the first analysis, we can see that the correlation between the presence of the initial topicalized constituent and (S) $\mathrm{V}(\mathrm{O})(0.234)$ is less strong than the correlation between the absence of the topicalized initial constituent and (S)V(O)/SVO in the second (0.374) and third analysis (0.594). While the first analysis showed reversibility to be a significant factor in predicting (S)V(O) pattern, it was not significant in the second and third analyses. CA was found to be significant only in the third analysis. With respect to social factors, gender was significant in all analyses, with women favouring $(\mathrm{S}) \mathrm{V}(\mathrm{O}) / \mathrm{SVO}$ compared to men who disfavoured this pattern. The second and third analyses showed that the youngest signers favoured $(\mathrm{S}) \mathrm{V}(\mathrm{O})$, whilst the age of acquisition was not significant in any of the three analyses.

\subsection{Locative state-of-affairs}

\subsubsection{Canonical structure}

As can be seen in Figure 4, locative state-of-affairs constituted 15 different patterns. Similar to some other SLs e.g., DTS (Engberg-Pedersen 1996), DGS (Perniss 2007a), BSL (Morgan et al. 
2008), the SZJ signers used mostly a first-GROUND-then-FIGURE order in 147 (73\%) instances, while $53(27 \%)$ examples had a first-FIGURE-then-GROUND order.

For locative state-of-affairs we also identified a subgroup of clauses that had a topicalized first constituent (top). There are five major patterns in locative clauses in SZJ, three of these introduce the larger/backgrounded entity - the ground first, and two begin by focusing on the smaller/foregrounded entity - the figure.

The most frequent pattern was GROUND-FIGURE-LOCATIVE RELATION, as in (38). The patterns GROUND-LOCATIVE RELATION-FIGURE and GROUND-FIGURE-DS (see 39) were produced an equal number of times, i.e. 32 (16\%). The fourth and the fifth most frequent patterns were FIGURE-LOCATIVE RELATION-GROUND (see 40) and FIGURE-GROUND-LOCATIVE RELATION (see 41).
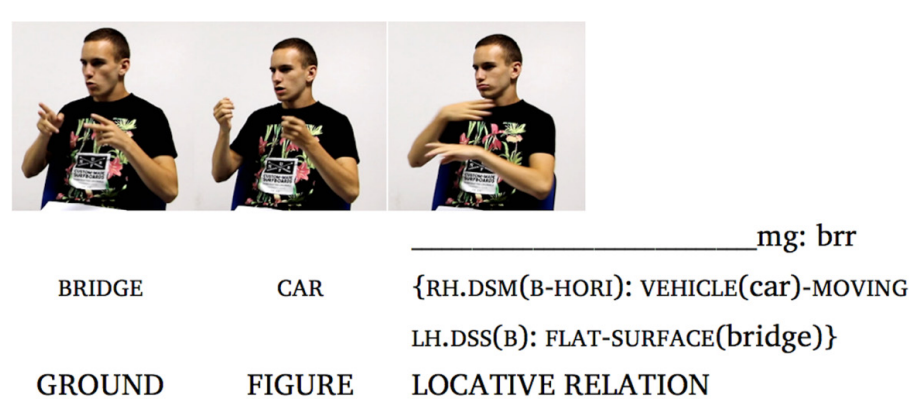

'A car is moving on a bridge.'

(39)

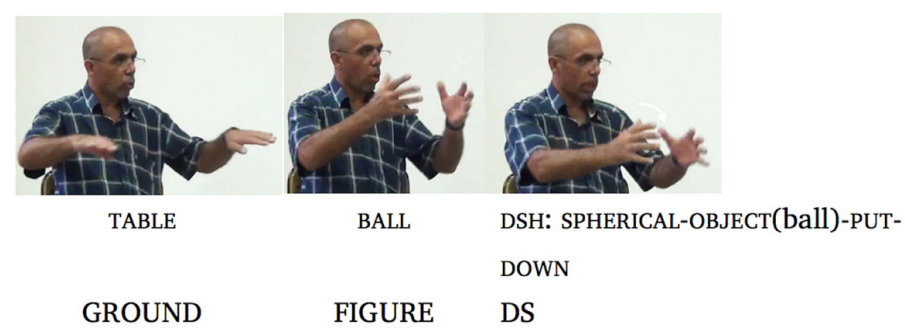

'A table with a ball being put on the table.'

(40)

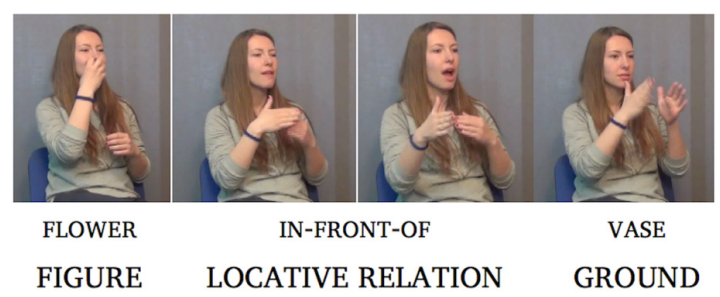

'Flowers (are) in front of a vase.'

(41)

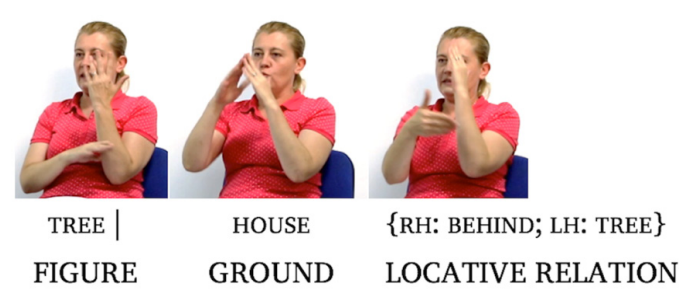

'A house (is) behind a tree.'

\subsubsection{The devices SZJ signers used to express the locative relation}

To encode locative relations SZJ signers relied on simultaneous constructions, prepositions, depicting signs (DS) and/or placement of lexical signs in the signing space (for an overview see Table 15 in Appendix).

As in some other studies on constituent order (e.g., Johnston et al. 2007; Vermeerbergen et al. 2007a), locative state-of-affairs resulted in the greatest number of simultaneous constructions most of which were found clause finally. In 74 instances (37\%) the simultaneous construction 
was the sole means of expressing the locative relation (see 38) whilst in four clauses a preposition was used first followed by a simultaneous construction, or DS was used first, to connect an entity with a particular locus in the signing space while a simultaneous construction established the relation between the GROUND and the FIGURE as in (42).

(42)

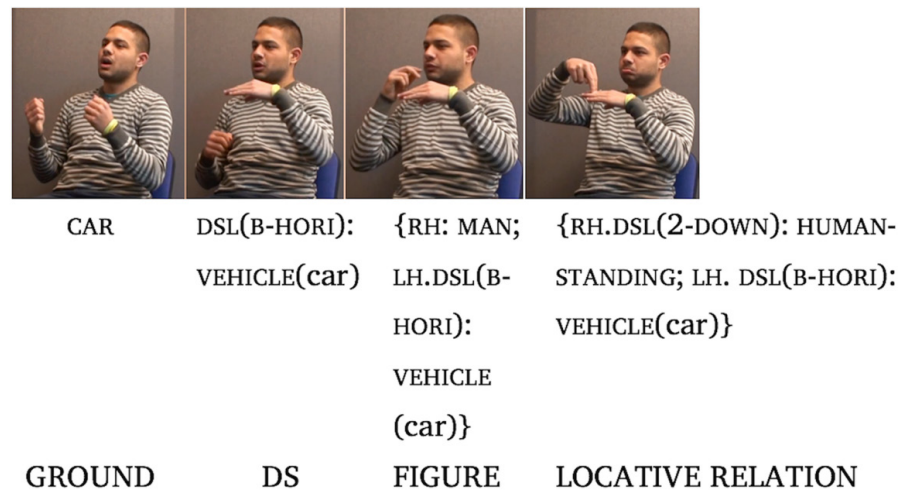

'(There is) a car with a man standing on the car.'

The second preferred means of expressing spatial relations in SZJ was via a preposition. A preposition occupied the medial position (see 40), or was used finally (see 43). A relatively frequent use of prepositions for expressing the locative relationship in SZJ is similar to the study on Auslan, VGT and ISL by Johnston et al. (2007), but different from the study on TiD by Özyürek et al. (2010) who report few prepositions in locative clauses.

(43)

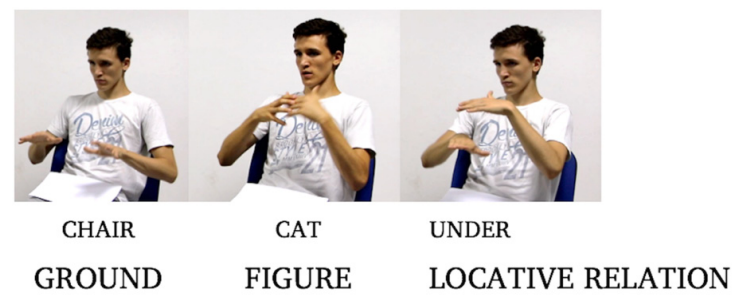

'(There is) a chair with a cat under the chair.'

In $51(26 \%)$ locative clauses, the signers used solely DS to establish the relation between the GROUND and the FIGURE in space, as in (44). In a few examples, locative relations were expressed through the juxtaposition of signs, i.e. through the direct placement of the sign for one entity at a particular location in the signing space with respect to the location of another entity (see 45).

(44)

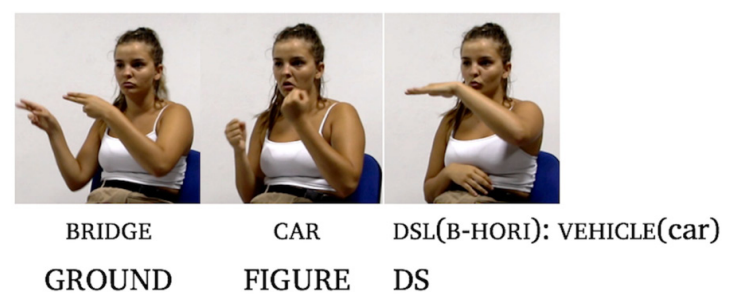

'(There is) a bridge with a car on the bridge.'

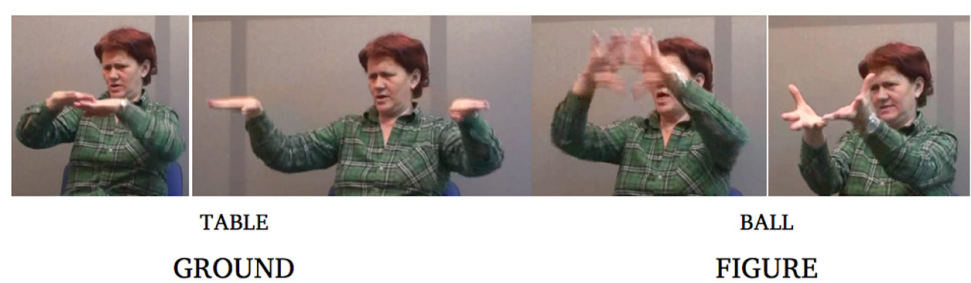

'(There is) a table with a ball on the table.' 


\section{Summary of the main findings}

\subsection{Constituent order in SZJ}

Judging by the data analysed in this study, the preferred order in non-locative clauses with at least one overt argument is SVO. When counting all patterns, SVO accounted for 211 (35\%) of analysed clauses. The verb and its core arguments can also be organized in the following manner: SOV, SV, SVOV, VO, OV, OSV, and OVS. OVS can be described as marginal, with only one attested example. In cases with an overt subject, the subject precedes the verb. When the subject is omitted in a transitive clause the order can be OV or VO, which is a finding also reported for FinSL (Jantunen 2013).

For locative state-of-affairs the principle order is GROUND-FIGURE-LOCATIVE RELATION. While in many SpLs the FIGURE tends to be mentioned before the GROUND (Grinevald 2006), in a number of SLs the GROUND comes first (see Engberg-Pedersen 1996 for DTS; Emmorey 1996 for ASL; Perniss 2007a for DGS; Vermeerbergen et al. 2007a for SASL). This tendency can perhaps be attributed to the visual-spatial modality of SLs. In a visual representation of a cup on a table through a drawing, for example, one is more likely to draw the table first before drawing the cup (Emmorey 1996: 178).

\subsection{Frequency of elliptical clauses}

The share of non-locative clauses with one or both core arguments elided, i.e. 285 (47\%) suggests that the participants in a SZJ clause need not be overtly expressed and that ellipsis is an important phenomenon in SZJ. This finding is not surprising in the context of other SL studies (e.g., Ferrara 2012, Jantunen 2013, Nordlund 2019). It seems that the environments in which ellipsis occurs in our examples are very similar to the ones reported for other SLs (Vermeerbergen et al. 2007a; Jantunen 2013; Johnston 2019a). For instance, we identified a number of what could be analysed as coordinated clauses exemplifying a pivot constraint in SZJ as in (35). The elided subject in the second clause is co-referential with the subject of the first clause and represents the case of zero anaphora.

In the findings for non-locative clauses we reported on several clauses missing one of the core arguments that are retrieved pragmatically. Thus, in (6), for example, the omitted subject has no syntactic antecedent. However, the use of CA with eye gaze directed at the sign space and head raised up as if to look up at a painting, and the verb LOOK2 which is modified, all show that there is a subject though it is not overtly expressed. The defocusing of the subject depends on prominence and specificity so when the subject is obvious, irrelevant, or unknown it is defocused (Langacker 2008). Both CA and DI verbs were shown to be used as part of agent defocusing strategies in other SLs (Rankin 2013; Nordlund 2019). However, clauses with elided core arguments do not necessarily require CA to be well-formed, as it can be seen in (46) where the subject is lexically unspecified, although it could be said that it is implied by the handling handshape of the verb that is associated with the agent (see Benedicto \& Brentari 2004).

(46)

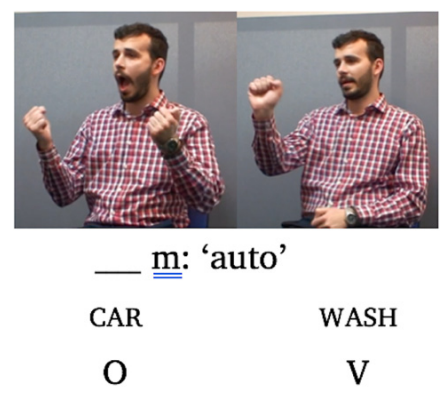

' A car is being washed.'

\subsection{Transitivity}

As already suggested in the annotation section above determining transitivity in some instances was challenging. While in (3) the preceding context and CA make it clear that the verb is intended transitively, the isolated verb-only clause BUILD that co-occurs with CA showing the action is carried out 'with effort' is more ambiguous. It could be analysed as transitive with 
omitted arguments '(someone) is building (a wall) with effort' where the iconically motivated form of the sign BUILD inherently implies an object i.e. 'laying of bricks' while CA imitates the action of a subject. BUILD in this sense may be one of those transitive verbs that are free to omit their object when it can be deduced from the context or when its specification is irrelevant (Börstell et al. 2019). Alternatively, BUILD can have an intransitive meaning with one omitted argument 'someone is building with effort'. Determining transitivity was further complicated by some $15 \%$ of verb-only clauses that were simultaneous constructions as in (37) where two vehicles are shown moving one after the other. Here, two interpretations are possible. The verb-only clause could have a transitive reading 'a car is following a truck/a truck is being followed by a car', or it could be analysed as intransitive 'a car is moving behind a truck/ truck is moving in front of a car'. As already stated tagging verb-only clauses for transitivity was not attempted because of a number of examples such as (37). Tagging (37) as transitive/ intransitive would have meant relying on probability rather than usage-based frequencies (see Ferrara 2012; Börstell et al. 2019). Building on work by Thompson and Hopper, Ferrara (2012: 240) suggests that frequency may not be useful with partly lexicalized depicting signs in her data that involve showing and instantiate "singularities rather than tokens of types" and as such cannot be observed across many instances to reveal their typical argument structure. Ferrara further contends that in such cases intuition is similarly unhelpful as a depicting verb can have more than one interpretation and thus result in more than one analysis of a predicate-argument structure.

\subsection{Semantic factors}

As regards the semantic factors, our data confirm the Human First Principle (Meir et al. 2017) i.e. the tendency for an animate human entity to be introduced before an inanimate non-human one in non-reversible state-of-affairs. The statistical analyses of the transitive clauses with overt arguments showed that reversibility is not significant in predicting SVO in SZJ (cf. a finding on reversibility not being an important factor in predicting constituent order in FinSL in Jantunen 2008). Nevertheless, based on absolute numbers SVO seems to be the preferred order in clauses for reversible state-of-affairs. The preference for SVO was observed in other SLs and frequently ascribed to communication pressures to resolve the semantic roles of two human entities (Meir et al. 2017). Looking at clauses with overt arguments the second most frequent order for clauses describing reversible state-of-affairs is SOV. In FinSL (Jantunen 2008), for example, SOV has been proposed to occur mainly when there is a pointing sign (PT) which serves to disambiguate between the subject and object. We also found examples with PT in SOV clauses for reversible state-of-affairs, as the one in (47) where PT is associated with the object of the action. In another clause in (48), the adverbial BEHIND and the directionality of the indicating verb PULL help distinguish between the subject and the object.

$\begin{array}{lllll}\text { WOMAN } & \text { PT:LOC } & \text { MAN } & \text { PT:LOC/DET } & \text { STROKE-CHEEK } \\ \text { S } & & \text { O } & & \text { V }\end{array}$

'A woman is stroking a cheek of that man there/in front of her.'

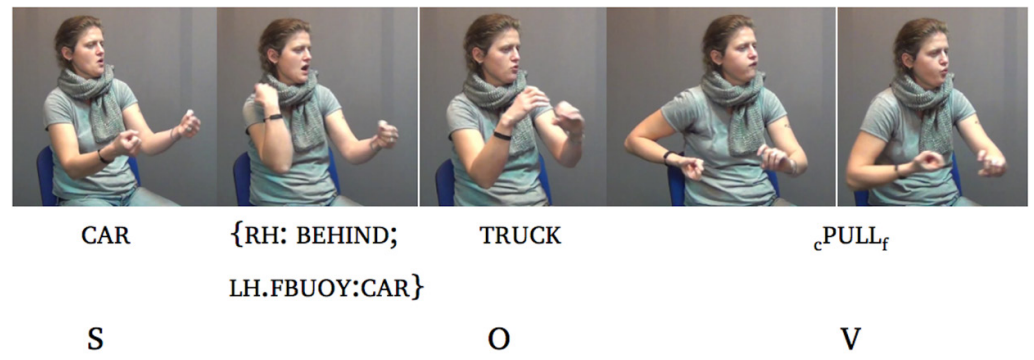

'A car behind a truck is pulling the truck.'

In some other SOV clauses, distinguishing between the subject and the object seems only to be possible through ordering the elements as there is no marking which could disambiguate the roles. It could be that placing subject and object together conforms to the iconic sequential order principle whereby the agent that is more topical is expected to occupy clause-initial position in a neutral active clause (Givón 2001: 36). 


\subsection{Verb type and CA}

With respect to verb type, our results are in line with certain findings reported for other SLs. Transitive declarative clauses with VPs are usually SVO (see Johnston \& Schembri 2007). In fact, the statistical analysis of transitive clauses with overt arguments showed that VPs in SZJ strongly favour SVO. Furthermore, SVO clauses with overt arguments disfavour the presence of CA. LI verbs as the most frequent verb type were prevalent in SVO clauses, but occurred commonly in verb-final clauses too. The suggestion made for other SLs, such as HKSL or HZJ, that the presence of a (modified) DI verb usually results in verb final order (see Sze 2003; Milković 2006) has not materialized in our data as the majority of (modified) DI verbs occurred in SVO. Furthermore, modification was more frequently observed in non-reversible than reversible category.

As for a correlation between modification of DI verbs and CA it is only in the non-reversible category that the majority of modified DI verbs co-occurred with CA, 21 of 32. This finding echoes Fenlon et al.'s (2018) conclusion for DIs in BSL that show that CA tends to co-occur with modification. However, it should be noted that our dataset is too limited to make any conclusive arguments concerning CA and constituent order. The relative scarcity of examples of CA can be explained by the fact that $\mathrm{CA}$ is a device used in narratives more than in any other register (Ferrara \& Johnston 2014), and thus would not be expected to be as common in these elicited examples.

Further, our data suggest that transitive verb final clauses favour VDs. This echoes, for example, the findings for DTS (Engberg-Pedersen 2002) and HKSL (Sze 2003), both proposed SVO languages in which arguments come first when there is a VD present.

\subsection{Simultaneous constructions and depicting sign location}

Simultaneous constructions mostly consisting of two DS usually occurred clause finally and were prevalent in locative clauses. This finding provides counter-evidence to the observation previously made about the lack of classifier morphemes in SZJ (cf. Polovina \& Dimić 2009).

A more specific finding related to DS in some SLs (Jantunen 2008; Özyürek et al. 2010) is the tendency to place them right after the first constituent of the predicate in locative clauses. Even though we found such instances, they did not occur consistently in locative clauses. These DS attribute a locus to the previously introduced entity, a nominal. The use of space by means of DS is a way of achieving spatial coherence in SL discourse (Perniss 2007b). In our data, the structure which includes a noun and DSL, introduced at the beginning, was usually topicalized, i.e. followed by a nod and a pause. A DSL was produced on the signer's non-dominant hand and was held throughout the articulation of subsequent signs on the dominant hand (see 42). We also found instances of DSL attributing a spatial locus to a human referent in non-locative clauses, as in (49). The same DSL also occurred in a simultaneous construction, as in (50).

(49)

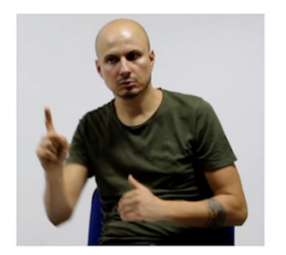

DSL(1-VERT): HUMAN-AT-LOCATION

(50)

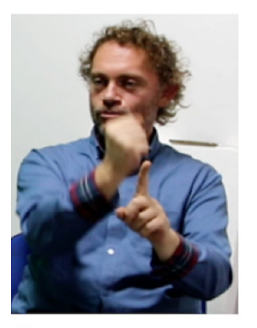

\{RH: STAB; LH.DSL(1-HORI): HUMAN-AT-LOCATION $\left.{ }_{\mathrm{f}}\right\}$

Another sign we encountered that resembles a DSL was PERSON (see 51). This sign has been observed in other SLs (e.g., Swedish Sign Language or STS Bergman \& Wallin 2003) with the same referring function. It occurs after a noun in a noun phrase and is called a "noun classifier" (Bergman \& Wallin 2003: 37). It exhibits non-manual characteristics such as eye 
contact with the addressee during the whole phrase and a mouthing that spreads across both elements of the noun phrase.
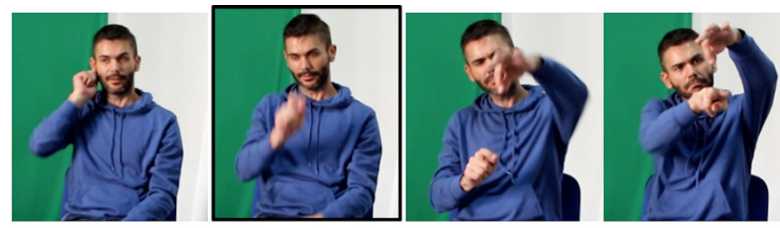

GIRL

PERSON

STRING

$\mathrm{O}$

$S$

$\mathrm{V}$

\{RH: CUT-WITH-SCISSORS; LH.FBUOY:

STRING\}

'A girl is cutting a string.'

In DGS, for example, PERSON can be treated as a person agreement marker (Steinbach \& Pfau 2007) that only combines with entities ranked high on the animacy scale and with unmodified DI verbs. More recently, Börstell (2019) and Bross (2020) have suggested for STS and DGS respectively that PERSON is in fact a differential object marker combining with a definite, affected, animate object. Such or a similar suggestion in the case of SZJ can be made after examining usage-based frequencies.

\subsection{Non-manual signals and topicalization}

In terms of non-manual markers indicative of topicalization, i.e. a nod, pause, squint etc. the statistical analyses encompassing transitive clauses with overt arguments suggest that SVO could be the neutral order in SZJ as it disfavours the presence of a topicalized constituent.

Based on the number of clauses with a topicalized constituent, 218 (34\%) for non-locative state-of-affairs and 109 (55\%) for locative state-of-affairs, the issue of topicalization in SZJ and non-manual signals associated with it require further analysis. More specifically, the presence of a non-manual marker in reversible SOV and OSV clauses needs to be examined more closely.

\subsection{Gender and age}

The statistical analyses of social categories that included gender for non-locative clauses revealed that women favour $(\mathrm{S}) \mathrm{V}(\mathrm{O}) / \mathrm{SVO}$. This could be a result of women preferring those forms of a language (for SpLs see Labov 1990, for SLs Mulrooney 2001) which tend to be perceived as prestigious (Cheshire 1998). Though the Serbian (spoken) language does not rely on word order as much as English, for example, its neutral word order is SVO (Klajn 2005). As deaf education in Serbia still predominantly uses signing in Serbian word order as the language of instruction, it may be regarded as a prestigious variety by the Serbian deaf community.

Furthermore, in the statistical analyses that included only transitive clauses with overt argument(s), the youngest group of signers were found to favour SVO, compared to the older signers who disfavoured SVO. It has been suggested for BSL (Woll 1991) and VGT (Vermeerbergen 1996), for example, that younger signers may experience more influence from the ambient SpL in their signing. Thus, signing in SVO among younger SZJ signers may be a result of the Serbian language influence. Again, this needs more investigation.

\section{Discussion}

The Volterra drawings were designed and subsequently used by researchers with the intention of eliciting prototypical transitive clauses containing a predicate and two overt arguments that would provide a first indication of (basic) constituent order in a SL. However, the original study as the studies after it showed that even in a relatively controlled experimental setting signers tend to omit arguments. If one were to account for clauses with overt constituents only, one could easily do so, though a significant number of elliptical clauses would be left aside. This kind of approach would have serious implications for the conclusions concerning the nature of the basic unit of analysis, the nature of symbolic relations between the constituents in such a unit and consequently the claim that there is a basic constituent order in a language. 
Some of the 'structurally incomplete' utterances in the dataset of the present study point at the possible drawbacks with respect to the presentation of the elicitation material that may have affected some of the patterns extracted. It could be that the absence of arguments in the isolated clause BUILD is the result of the fact that it is the action which is the contrasting element (building versus painting) between the two drawings so that mentioning verb is enough for the addressee to know to which drawing the signer is referring (see Vermeerbergen et al. 2007a: 37). However, clauses such as BUILD were produced rarely while clauses with subject and/or object omitted within a multi-clausal string were more common. In such instances and in the absence of conventional marking pragmatic inferencing and the strategy of 'showing' using highly iconic structures (Cuxac 1999; 2000) rather than 'telling' may play a role. The entrenchment of these iconic structures is a matter of degree (Ferrara 2012; Puupponen 2019; Johnston 2019a): it is possible to distinguish between unconventionalised signs whose meaning is highly context dependent as they do not have a fixed form-meaning pairing (recall instances of CA from this study), and symbolic indexicals that are partly lexicalized such as depicting signs. Even many signs that are conventional but iconic (e.g., PAINT in this study) can index space meaningfully by, for example, directing at a location. This property gives them a possibility of changing their meaning and form indexically which is quite unlike spoken symbolic indexicals (Johnston 2019a).

So, what about a clause in SZJ? It seems from what we could observe in the dataset of this study that signers rely on various representational strategies for producing utterance units, as discussed by Ferrara and Hodge (2018). Some of these units use overt manual signs to identify participants and processes in a clause (cf. Jantunen 2008; Hodge 2013). On the other hand, there are utterance units which use primarily visual representations or enactment and use a mixture of more or less conventionalised symbols: these may not be recognised as clauses in the traditional sense in linguistics. Locative clauses where placement and movement of signs between or towards loci in space are so prevalent, for example, suggest that visual representation of spatial relations may not best be seen as an example of linguistic encoding in the traditional sense i.e. they appear to involve less 'telling' than 'showing'. Iconicity that underlies this 'showing' strategy and pervades SL utterances at different levels of organisation together with the lack of conventional marking call for a careful consideration of a 'constituent' and a basic unit of analysis in SZJ and point at SZJ as a heterogeneous system (see Schembri 2001), involving a mixture of telling, indicating, and depicting (Ferrara \& Hodge 2018). This semiotically diverse grammatical system involves a continuum of conventionality (see Vermeerbergen 2006; Jantunen 2017). Like Ferrara and Hodge (2018), we would argue that any theory of grammar must be able to account for all aspects of the heterogeneous system we see here.

\section{Conclusion}

In this article, we have investigated constituent order in declarative clauses in SZJ. The most frequent order is subject before object. In single transitive clauses with two overt arguments, the most frequent and possibly neutral order is SVO. In intransitive clauses, the most frequent pattern is SV. The most frequent ordering in locative clauses is GROUND-first-then-FIGURE. As our data indicate other orders are also attested, although they occur less frequently.

Declarative clauses in SZJ seem to adhere to basic principles of sequential organization of clauses found in other SLs. However, simultaneity, the use of space, core argument omission, and the use of CA challenge the traditional notion of a clause as a sequential string of constituents. Though a clause as the basic unit of analysis in typological studies on constituent order in SZJ and SLs in general needs to be re-examined, the current study has shown that it is possible to analyse utterances in SZJ from a "clause-level perspective" (cf. Hodge 2013). Topicalization, the use of DS, core argument omission or implicit argument presence as a result of agent defocusing strategies via, for example, CA may alter the neutral constituent order. The evidence of these factors in our data questions the previous finding about constituent order in SZJ as the most important characteristic that can resolve structural ambiguity (Polovina \& Dimić 2009), and raises the question about prominence of grammatical meanings and grammatical relations in SZJ. Gaining a more detailed insight into the typological nature of SZJ clearly requires further analysis of different types of data. 


\section{Additional file}

The additional file for this article can be found as follows:

- Appendix. 1 Notations \& abbreviations; 2 Overview of the participants; 3 Tables. DOI:

https://doi.org/10.5334/gigl.1357.s1

\section{Acknowledgements}

We thank our deaf participants and Mihailo Gordić who helped with data collection. We also thank our anonymous reviewers for their very constructive feedback.

\section{Funding information}

This research was supported by the UGent BOF-doctoral scholarship, BOF.DOC.2015.0057.01 and the Civil Society Scholar Award, grant number IN2015-22556.

\section{Competing interests}

The authors have no competing interests to declare.

\section{Author contributions}

The first author wrote the text, collected, annotated, and analysed the data. The second, third and fourth author contributed to the text and reviewed data analysis. The third author reviewed the statistical analysis.

\section{Author affiliations}

Dragana Raičević Bajić (D) orcid.org/0000-0002-6052-4143

Linguistics Department, Ghent University, Blandijnberg 2, 9000 Ghent, Belgium

Myriam Vermeerbergen (D) orcid.org/0000-0002-3038-2308

KU Leuven, Faculteit Letteren, Campus Antwerpen, Sint-Andriesstraat 2, 2000 Antwerpen, Belgium

Adam Schembri (D) orcid.org/0000-0002-8814-5911

English Language and Linguistics, University of Birmingham, Birmingham, B15 2TT, UK

Mieke Van Herreweghe (D) orcid.org/0000-0001-8898-2202

Ghent University, Campus Ufo - Rectorate, Sint-Pietersnieuwstraat 25, 9000 Ghent, Belgium

\section{References}

Anderson, Lloyd B. 1978. Historical Change and Stability of American Sign Language. Unpublished manuscript. Washington, DC: Gallaudet College.

Benedicto, Elena \& Diane Brentari. 2004. Where did all the arguments go?: Argument-changing properties of classifiers in ASL. Natural Language \& Linguistic Theory 22(4). 743-810. DOI: https://doi. org/10.1007/s11049-003-4698-2

Bergman, Brita \& Lars Wallin. 2003. Noun and verbal classifiers in Swedish Sign Language. In Karen Emmorey (ed.), Perceptives on Classifier Constructions in Sign Languages, 35-52. Mahwah, New Jersey: Lawrence Erlbaum Associates.

Börstell, Carl. 2019. Differential object marking in sign languages. Glossa: A Journal of General Linguistics 4(1). 3. DOI: https://doi.org/10.5334/gigl.780

Börstell, Carl, Tommi Jantunen, Vadim Kimmelman, Vanja de Lint, Johanna Mesch \& Marloes Oomen. 2019. Transitivity prominence within and across modalities. Open Linguistics 5. 666-689. DOI: https://doi.org/10.1515/opli-2019-0037

Boyes Braem, Penny. 2001. Functions of the mouthings in the signing of Deaf early and late learners of Swiss German Sign Language (DSGS). In Penny Boyes Braem \& Rachel Sutton-Spence (eds.), The hands are the head of the mouth: the mouth as articulator in sign languages, 99-131. Hamburg: Signum Press.

Brennan, Mary \& Graham H. Turner (eds.). 1994. Word Order Issues in Sign Language: Working papers. Durham: International Sign Linguistics Association.

Cheshire, Jenny. 1998. The relationship between language and sex in English. In Michael D. Linn (ed.), Handbook of Dialects and Language Variation, 403-418. San Diego, California: Academic Press. 
Coerts, Jane. 1994. Constituent order in Sign Language of the Netherlands. In Mary Brennan \& Graham Turner (eds.), Word Order Issues in Sign Language: Working papers, 47-72. Durham: International Sign Linguistics Association.

Cormier, Kearsy, Sandra Smith \& Zed Servcikova-Sehyr. 2015. Rethinking constructed action. Sign Language and Linguistics 18(2). 167-204. DOI: https://doi.org/10.1075/sll.18.2.01 cor

Crasborn, Onno \& Han Sloetjes. 2008. Enhanced ELAN functionality for sign language corpora. In Proceedings of LREC 2008, Sixth International Conference on Language Resources and Evaluation.

Croft, William. 2001. Radical Construction Grammar: Syntactic Theory in Typological Perspective. New York: Oxford University Press. DOI: https://doi.org/10.1093/acprof:oso/9780198299554.001.0001

Cuxac, Christian. 1999. The expression of spatial relations and the spatialization of semantic relations in French Sign Language. In Catherine Fuchs \& Stéphane Robert (eds.), Language Diversity and Cognitive Representations, 123-142. Amsterdam/Philadelphia: John Benjamins. DOI: https://doi.org/10.1075/ hcp.3

de Quadros, Ronice Müller. 1999. Phrase Structure of Brazilian Sign Language. Porto Alegre: Pontifícia Universidade Cátolica do Rio Grande do Sul dissertation.

Degand, Liesbeth \& Simone Ann Catherine. 2009. On identifying basic discourse units in speech: theoretical and empirical issues. Discours [Online] 4. (Available online at https://journals.openedition. org/discours/5852; Accessed on 2020-05-06.). DOI: https://doi.org/10.4000/discours. 5852

Dryer, Matthew S. 1997. Are grammatical relations universal? In Joan Bybee, John Haiman \& Sandra A. Thompson (eds.), Essays on Language Function and Language Type, 115-143. Amsterdam: John Benjamins. DOI: https://doi.org/10.1075/\%.82

Dryer, Matthew S. 2005. Order of subject, object, and verb. In Martin Haspelmath, Matthew S. Dryer, David Gil \& Bernard Comrie (eds.), The World Atlas of Language Structures, 330-333. Oxford: Oxford University Press.

É. Kiss, Katalin. 1995. Discourse configurational languages: Introduction. In Katalin É. Kiss (ed.), Discourse configurational languages, 3-27. New York: Oxford University Press.

Emmorey, Karen. 1996. The confluence of space and language in signed language. In Paul Bloom, Mary A. Peterson, Lynn Nadel \& Merrill F. Garett (eds.), Language and space, 171-209. Cambridge, MA: MIT Press.

Emmorey, Karen. 2002. Language, Cognition, and the Brain: Insights from Sign Language Research. Mahwah, NJ: Lawrence Erlbaum and Associates. DOI: https://doi.org/10.4324/9781410603982

Engberg-Pedersen, Elisabeth. 1996. Space in Danish Sign Language: the semantics and morphosyntax of the use of space in a visual language. Hamburg: Signum.

Engberg-Pedersen, Elisabeth. 2002. Grammatical relations in Danish Sign Language: topic and subject. In Anneli Pajunen (ed.), Mimesis, sign, and the evolution of language, 5-40. Publications in General Linguistics 3. University of Turku.

Fenlon, Jordan, Kearsy Cormier \& Adam Schembri. 2018. Modification of indicating verbs in British Sign Language: A corpus based study. Language 94(1). 84-118. DOI: https://doi.org/10.1353/ lan.2018.0002

Fenlon, Jordan, Tanya Denmark, Ruth Campbell \& Bencie Woll. 2007. Seeing sentence boundaries. Sign Language \& Linguistics 10(2). 177-200. DOI: https://doi.org/10.1075/sll.10.2.06fen

Ferrara, Lindsay. 2012. The grammar of depiction: Exploring gesture and language in Australian Sign Language (Auslan). Sydney: Macquarie University dissertation.

Ferrara, Lindsay \& Gabrielle Hodge. 2018. Language as description, indication and depiction. Frontiers in Psychology. DOI: https://doi.org/10.3389/fpsyg.2018.00716

Ferrara, Lindsay \& Trevor Johnston. 2014. Elaborating who's what: A study of depiction and grammar in Auslan (Australian Sign Language). Australian Journal of Linguistics 34(2). 193-215. DOI: https://doi. org/10.1080/07268602.2014.887405

Fischer, Susan D. \& Wynne Janis. 1990. Verb sandwiches in ASL. In Siegmund Prillwitz \& Thomas Vollhaber (eds.), Current trends in European sign language research: Proceedings of the 3rd European Congress on Sign Language Research, Hamburg, 1989, 279-294. Hamburg: Signum.

Gabarró-López, Sílvia \& Laurence Meurant. 2016. Slicing your SL data into Basic Discourse Units (BDUs): Adapting the BDU model (syntax + prosody) to signed discourse. In Workshop proceedings: $7^{\text {th }}$ Workshop on the Representation and Processing of sign languages: Corpus mining, 81-89.

Gibson, Edward, Steven T. Piantadosi, Kimberly Brink, Leon Bergen, Eunice Lim \& Rebecca Saxe. 2013. A noisy-channel account of crosslinguistic word-order variation. Psychological Science, 24(7). 1079-1088. DOI: https://doi.org/10.1177/0956797612463705

Givón, Talmy. 2001. Syntax. Vol. 1. Amsterdam: John Benjamins Publishing Company. DOI: https://doi. org/10.1075/\%.50

Grinevald, Colette. 2006. The expression of static location in a typological perspective. In Maya Hickmann \& Stéphane Robert (eds.), Space in languages. Linguistic systems and cognitive categories, 29-58. Amsterdam: John Benjamins. DOI: https://doi.org/10.1075/tsl.66 
Hall, Matthew L., Rachel I. Mayberry \& Victor S. Ferreira. 2013. Cognitive constraints on constituent order: Evidence from elicited pantomime. Cognition 129(1). 1-17. Elsevier B.V. DOI: https://doi. org/10.1016/j.cognition.2013.05.004

Hodge, Gabrielle, Lindsay Ferrara \& Trevor Johnston. 2011. Using prosody and grammar to describe natural discourse in Auslan. Paper presented at the $33^{\text {rd }}$ Annual Meeting of the German Linguistics Society. University of Gottingen, Germany, February 23-25, 2011.

Hodge, Gabrielle. 2013. Patterns from a signed language corpus: Clause-like units in Auslan (Australian Sign Language). Sydney: Macquarie University dissertation.

Jantunen, Tommi. 2008. Fixed and free: Order of the verbal predicate and its core arguments in declarative transitive clauses in Finnish Sign Language. SKY Journal of Linguistics 21. 83-123.

Jantunen, Tommi. 2013. Ellipsis in Finnish Sign Language. Nordic Journal of Linguistics 36(3). 303-332. DOI: https://doi.org/10.1017/S0332586513000292

Jantunen, Tommi. 2017. Constructed action, the clause, and the nature of syntax in Finnish Sign Language. Open Linguistics 3. 65-85. DOI: https://doi.org/10.1515/opli-2017-0004

Johnson, Daniel E. 2009. Getting off the GoldVarb standard: Introducing Rbrul for mixed- effects variable rule analysis. Language and Linguistics Compass 3(1). 359-383. DOI: https://doi.org/10.1111/j.1749818X.2008.00108.x

Johnston, Trevor \& Adam Schembri. 2006. Identifying clauses in signed languages: Applying a functional approach. Paper presented at the DGfS [Deutsche Gesellschaft für Sprachwissenschaft] 2006 workshop How to recognize a sentence when you see one: methodological and linguistic issues in the creation of sign language corpora. Bielefeld, Germany, February 23-24, 2006.

Johnston, Trevor \& Adam Schembri. 2007. Australian Sign Language: An Introduction to Sign Language Linguistics. Cambridge: Cambridge University Press. DOI: https://doi.org/10.1017/ CB09780511607479

Johnston, Trevor, Myriam Vermeerbergen, Adam Schembri \& Lorraine Leeson. 2007. 'Real data are messy': Considering cross-linguistic analysis of constituent ordering in Auslan, VGT, and ISL. In Pamela M. Perniss, Roland Pfau \& Markus Steinbach (eds.), Visible Variation. Comparative Studies on Sign Language Structure, 207-244. Berlin: Mouton de Gruyter. DOI: https://doi. org/10.1515/9783110198850

Johnston, Trevor. 1996. Function and medium in the forms of linguistic expression found in a sign language. In William H. Edmondson \& Ronnie Wilbur (eds.), International Review of Sign Linguistics 1. 57-94. Mahwah, NJ: Lawrence Earlbaum.

Johnston, Trevor. 2019a. Clause constituents, arguments, and the question of grammatical relations in Auslan (Australian Sign Language): a corpus-based study. Studies in Language 43(4). 944-998. DOI: https://doi.org/10.1075/sl.18035.joh

Johnston, Trevor. 2019b. Auslan Corpus Annotation Guidelines. Sydney, Australia: Macquarie University.

Kimmelman, Vladim. 2012. Word order in Russian Sign Language. Sign Language Studies 12(3). 414-445. DOI: https://doi.org/10.1353/sls.2012.0001

Klajn, Ivan. 2005. Gramatika srpskog jezika [the Grammar of the Serbian language]. Beograd: Zavod za udžbenike i nastavna sredstva.

Labov, William. 1990. The intersection of sex and social class in the course of linguistic change. Language Variation and Change 2. 205-254. DOI: https://doi.org/10.1017/S0954394500000338

Langacker, Ronald W. 2008. Cognitive Grammar: A Basic Introduction. New York: Oxford University Press. DOI: https://doi.org/10.1093/acprof:oso/9780195331967.001.0001

Leeson, Lorraine \& John Saaed. 2012. Word order. In Roland Pfau, Markus Steinbach \& Bencie Woll (eds.), Sign Language: An International Handbook, 245-265. Berlin/Boston: Mouton de Gruyter. DOI: https://doi.org/10.1515/9783110261325

Li, Charles \& Sandra Thompson. 1976. Subject and topic: a new typology of language. In Charles Li \& Sandra Thompson (eds.), Subject and topic, 456-489. New York: Academic Press.

Liddell, Scott K. 2003. Grammar, gesture, and meaning in American Sign Language. Cambridge: Cambridge University Press. DOI: https://doi.org/10.1017/CBO9780511615054

Lucas, Ceil, Robert Bayley, Clayton Valli, Mary Rose \& Alyssa Wulf. 2001. Sociolinguistic variation. In Ceil Lucas (ed.), The Sociolinguistics of Sign Languages, 61-111. Cambridge: Cambridge University Press. DOI: https://doi.org/10.1017/CBO9780511612824

McKee, Rachel, Adam Schembri, David McKee \& Trevor Johnston. 2011. Variable “subject” presence in Australian Sign Language and New Zealand Sign Language. Language Variation and Change 23(3). 375-398. DOI: https://doi.org/10.1017/S0954394511000123

Meir, Irit, Mark Aronoff, Carl Börstell, So-One Hwang, Deniz Ilkbasaran, Itamar Kastner, Ryan Lepic, Adi Lifshitz Ben-Basat, Carol Padden \& Wendy Sandler. 2017. The effect of being human and the basis of grammatical word order: Insights from novel communication systems and young sign languages. Cognition 158. DOI: https://doi.org/10.1016/j.cognition.2016.10.011

Milković, Marina, Sandra Bradarić-Jončić \& Ronnie B. Wilbur. 2006. Word order in Croatian Sign Language. Sign Language \& Linguistics 9(1/2). 169-206. DOI: https://doi.org/10.1075/sll.9.1.10mil general linguistics

DOI: 10.5334 /gjgl.1357 
Morgan, Gary, Rosalind Herman \& Bencie Woll. 2002. The development of complex verb constructions in British Sign Language. Journal of Child Language 29(3). 655-675. DOI: https://doi.org/10.1017/ S0305000902005184

Morgan, Gary, Rosalind Herman, Isabelle Barriere \& Bencie Woll. 2008. The onset and mastery of spatial language in children acquiring British Sign Language. Cognitive Development 23(1). 1-19. DOI: https://doi.org/10.1016/j.cogdev.2007.09.003

Mulrooney, Kristin. 2001. Gender variation in fingerspelling in American Sign Language. Paper presented at the American Dialect Society. Washington, DC, January.

Napoli, Dona Jo \& Rachel Sutton-Spence. 2014. Order of the major constituents in sign languages: implications for all language. Frontiers in Psychology 5. Article 376. DOI: https://doi.org/10.3389/ fpsyg.2014.00376

Nordlund, Sanna. 2019. Agent defocusing in two-participant clauses in Finnish Sign Language. Glossa: $a$ journal of general linguistics 4(1). 82. DOI: https://doi.org/10.5334/gigl.801

Oomen, Marloes \& Vadim Kimmelman. 2019. Body-anchored verbs and argument omission in two sign languages. Glossa: a journal of general linguistics 4(1). 42. DOI: https://doi.org/10.5334/gjgl.741

Özyürek, Asli, Inge Zwitserlood \& Pamela Perniss. 2010. Locative expressions in signed languages: a view from Turkish Sign Language (TiD). Linguistics 48(5). 1111-1145. DOI: https://doi.org/10.1515/ ling.2010.036

Padden, Carol. 1988. Interaction of Morphology and Syntax in American Sign Language. London: Routledge. DOI: https://doi.org/10.4324/9781315449685

Perniss, Pamela. 2007a. Space and iconicity in German Sign Lanuage (DGS). Nijmegen: Radboud Universiteit dissertation. DOI: https://doi.org/10.1075/sll.11.1.17per

Perniss, Pamela. 2007b. Achieving spatial coherence in German Sign Language narratives: The use of classifiers and perspective. Lingua 117. 1315-1338. DOI: https://doi.org/10.1016/j.lingua.2005.06.013

Polovina, Vesna \& Nadežda Dimić. 2009. Gramatičke kategorije u srpskom znakovnom jeziku [Grammatical categories in Serbian Sign Language]. Istraživanja u specijalnoj edukaciji i rehabilitaciji, 299-311. Beograd: FASPER.

Prince, Ellen. 1981. Toward a taxonomy of given-new information. In Peter Cole (ed.), Radical Pragmatics, 91-136. New York: Academic Press.

Puupponen, Anna. 2019. Towards understanding nonmanuality: a semiotic treatment of signers' head movements. Glossa: a journal of general linguistics 4(1). 31-39. DOI: https://doi.org/10.5334/gjgl.709

Raicevic, Dragana, Myriam Vermeerbergen \& Mieke Van Herreweghe. 2017. Basic constituent order in Serbian Sign Language: A first study. Poster presented at the conference Language as a Form of Action. Rome, Italy, June 21-23, 2017.

Rankin, Miako. 2013. Form, Meaning, and Focus in American Sign Language. Washington, DC: Gallaudet University Press.

Rissman, Lilia, Laura Horton, Molly Flaherty, Ann Senghas, Marie Coppola, Diane Brentari \& Susan Goldin-Meadow. 2020. The communicative importance of agent-backgrounding: Evidence from homesign and Nicaraguan Sign Language. Cognition 203. 104332. DOI: https://doi.org/10.1016/j. cognition.2020.104332

Schembri, Adam. 2001. Issues in the analysis of polycomponential verbs in Australian Sign Language (Auslan). Sydney: University of Sydney PhD dissertation.

Schembri, Adam, David McKee, Rachel McKee, Sara Pivac, Trevor Johnston \& Della Goswell. 2009. Phonological variation and change in Australian and New Zealand Sign Languages: The location variable. Language Variation and Change 21(2). 193-231. DOI: https://doi.org/10.1017/ S0954394509990081

Steinbach, Markus \& Roland Pfau. 2007. Grammaticalization of auxiliaries in sign languages. In Pamela M. Perniss, Roland Pfau \& Markus Steinbach (eds.), Visible Variation. Comparative Studies on Sign Language Structure, 303-339. Berlin: Mouton De Gruyter. DOI: https://doi. org/10.1515/9783110198850

Sze, Felix. 2003. Word order of Hong Kong Sign Language. In Anne Baker, Beppie van den Bogaerde \& Onno Crasborn (eds.), Cross-linguistic perspectives in sign language research. Selected papers from TISLR 2000, 163-192. Hamburg: Signum.

Sze, Felix. 2015. Is Hong-Kong Sign Language a topic-prominent language? Linguistics 53(4). 809-876. DOI: https://doi.org/10.1515/ling-2015-0021

Tagliamonte, Sali. 2006. Analysing Sociolinguistic Variation. Cambridge: Cambridge University Press. DOI: https://doi.org/10.1017/CBO9780511801624

Talmy, Leonard. 1975. Figure and ground in complex sentences. In Proceedings of the First Annual Meeting of the Berkeley Linguistics Society, 419-430. DOI: https://doi.org/10.3765/bls.v1i0.2314

Talmy, Leonard, 2003. Spatial structuring in spoken language and its relation to that in signed language. In Karen Emmorey (ed.), Perspectives on classifiers in signed languages, 169-195. Mahwah, NJ: Lawrence Erlbaum.

Thompson, Sandra A. \& Paul J. Hopper. 2001. Transitivity, clause structure, and argument structure: 
Evidence from conversation. In Joan Bybee and Paul Hopper (eds.), Frequency and the Emergence of Linguistic Structure, 27-60. Amsterdam: Benjamins. DOI: https://doi.org/10.1075/tsl.45.03tho

Van Herreweghe, Mieke \& Myriam Vermeerbergen. 2012a. Data collection. In Roland Pfau, Markus Steinbach \& Bencie Woll (eds.), Sign Language: An International Handbook, 1023-1045. Berlin/Boston: Mouton de Gruyter. DOI: https://doi.org/10.1515/9783110261325

Van Herreweghe, Mieke \& Myriam Vermeerbergen. 2012b. Verbal Predicates in Flemish Sign Language (VGT) and South African Sign Language (SASL). In Marleen Van Peteghem, Peter Lauwers, Els Tobback, Annemie Demol \& Laurence De Wilde (eds.), Le Verbe En Verve: Réflexions Sur La Syntaxe Et La Sémantique Verbales, 401-420. Ghent: Academia Press.

Vermeerbergen, Myriam. 1996. ROOD KOOL TIEN PERSOON IN. Morfo-syntactische aspecten van gebarentaal. Brussels: Vrije Universiteit Brussel dissertation.

Vermeerbergen, Myriam. 2006. Past and current trends in sign language research. Language \& Communication 26(2). 168-192. DOI: https://doi.org/10.1016/j.langcom.2005.10.004

Vermeerbergen, Myriam, Mieke Van Herreweghe, Philemon Akach \& Emily Matabane. 2007a. Constituent order in Flemish Sign Language (VGT) and South African Sign Language (SASL). A cross-linguistic study. Sign Language \& Linguistics 10(1). 25-54. DOI: https://doi.org/10.1075/sll.10.1.04ver

Vermeerbergen, Myriam, Lorraine Leeson \& Onno Crasborn. 2007b. Simultaneity and Signed Languages: Form and Function. Amsterdam/Philadelphia: John Benjamins Publishing Company. DOI: https://doi. org/10.1075/cilt.281

Volterra, Virginia, Alessandro Laudanna, Serena Corazza, Elena Radutsky \& Francesco Natale. 1984. Italian Sign Language: the order of elements in the declarative sentence. In Filip Loncke, Penny Boyes-Braem \& Yvan Lebrun (eds.), Recent research on European sign languages, 19-48. Lisse: Swets \& Zeitlinger B.V.

Woll, Bencie. 1991. Variation and Recent Change in British Sign Language. Final report to Economic and Social Research Council. University of Bristol: Centre for Deaf Studies.

TO CITE THIS ARTICLE: Raičević Bajić, Dragana, Myriam Vermeerbergen, Adam Schembri and Mieke Van Herreweghe. 2021. Constituent order in Serbian Sign Language declarative clauses. Glossa: a journal of general linguistics 6(1): 39. 1-32. DOI: https://doi.org/10.5334/ gjgl.1357

Submitted: 22 June 2020 Accepted: 29 January 2021 Published: 07 April 2021

\section{COPYRIGHT:}

(c) 2021 The Author(s). This is an open-access article distributed under the terms of the Creative Commons Attribution 4.0 International License (CC-BY 4.0), which permits unrestricted use, distribution, and reproduction in any medium, provided the original author and source are credited. See http:// creativecommons.org/ licenses/by/4.0/.

Glossa: a journal of general linguistics is a peer-reviewed open access journal published by Ubiquity Press. 